\title{
Fatigue Life Calculation Concepts for Structures with locally modified properties
}

\author{
Tim Medhurst ${ }^{1, a}$, Alfons Esderts ${ }^{1, b}$ and Rainer Masendorf ${ }^{1, c}$ \\ ${ }^{1}$ Institut für Maschinelle Anlagentechnik und Betriebsfestigkeit (IMAB), \\ Technische Universität Clausthal (TUC), Leibnizstrasse 32, \\ 38678 Clausthal-Zellerfeld, Germany \\ atim.medhurst@imab.tu-clausthal.de, balfons.esderts@imab.tu-clausthal.de, \\ rainer.masendorf@imab.tu-clausthal.de
}

Keywords: Low Cycle Fatigue, Incremental Step Test, cyclic hardening, work hardening, forming, additional forming elements, temperature influence on fatigue life

\begin{abstract}
The influence of forming on the cyclic behaviour of various thin sheet metals with austenitic phases is looked into, with the main focus lying on the variation of cyclic parameters and the progression of work hardening over the materials' fatigue life. There is a marked interaction of hardening due to increased dislocation density resulting from forming and hardening due to cyclic straining under varying strain amplitudes of strain controlled LCF testing. This is strongly dependant on the degree of forming and the amplitude of the following cyclic loading. Also, the temperature influence during forming of addtional forming elements in a temperature controlled die on the fatigue performance of austenitic and complex three phase steels was analysed, showing a marked influence of the forming temperature on the fatigue performance, enabling positive effects to be achieved by choosing suitable material specific forming temperatures.
\end{abstract}

\section{Introduction}

The collaborative research project SFB 675 is strongly focussed on improving metal structures and parts to be better suited to their intended use. This may affect any of the numerous characteristic properties normally associated with metal engineering structures. Of special interest though, is the localised, directed improvement of the specific strength properties of structures. These may be affected by the tensile strength of the material, its' ductility, the joining methods used and heat treatment before or after production, to name a few. The improvement of strength may be static, or, more importantly in many applications, also dynamic. An improved fatigue life is just as important as the static strength properties of a structure, making the investigation of fatigue properties vitally important for any method of creating improved structures, whatever the aim of the specific improvement may be.

This part project is focussed on describing the influences of the numerous manufacturing influences used in the whole research project on the fatigue behaviour of the involved materials and their joining processes. The main aim is to describe the effects of setting specialised local material properties on the fatigue life of a component. Because of the new and specialised nature of the local modifications, none of the existing methods are ideally suited to model the resulting effects. New experimental data has to be gathered to describe the ensuing effects of local modifications. Afterwards the experimental data has to be analysed to enable a model to be created which describes the fatigue life behaviour most accurately. A following fatigue life calculation based on the to be developed model will verify the findings.

In case of the part project $\mathrm{C} 2$, the main focus of the past work has been put on the influence of strengthening and cyclic hardening mechanisms found in steel sheets containing residual austenite phases or fully austenitic thin steel sheets. The large possible increase of fatigue strength as a result of cold forming these materials is described by parameters and a model, making it possible to integrate the strengthening effects into a fatigue life calculation. The to be developed and parameterised calculation concept will include all relevant forming and manufacturing parameters as well as local hardening effects to increase the reliability of fatigue life predictions. 


\section{Fatigue life estimation methods}

The most common method is the local strain concept, where strain values from elastic FE analyses are used in combination with Neuber's theory to predict the fatigue life using LCF derived fatigue life information. This method is currently state of the art for fatigue life calculations. With regard to local strengthening due to the forming process of austenitic steel parts with martensitic evolution during forming, fatigue life calculations become very complex due to the hardening caused by the high dislocation density resulting from the deep drawing process and cyclic work hardening as a result of operating loads. These strengthening influences lead to a very pronounced deviation from the strain-life curve of the material as delivered, causing large faults in the predicted cyclic fatigue life.

To build a sound basis for the inclusion of forming effects, experimental analyses like the ones presented in the following are indispensable. If fatigue data is available for various degrees of forming, it may soon be possible to include such effects in the calculation of fatigue life during the CAE process, making the optimisation of this aspect of the design much easier than currently possible.

\section{Strain controlled Low Cycle Fatigue Tests}

To characterise the cyclic behaviour of the available materials, strain controlled low cycle fatigue (LCF) tests were undertaken. Strain controlled tests are especially suited to accurately characterise the change of cyclic behaviour of thin sheet metals. Stress controlled fatigue tests are more difficult to accomplish due to the strong tendency of the materials towards cyclic creeping at stress amplitudes above their endurance fatigue limit, making an accurate assessment of the finite life fatigue strength almost impossible. Besides the cyclic coefficients of the material cannot be determined by stress controlled tests, making the resulting data unsuited for current fatigue life calculations such as the local stress concept. Stress-strain curves are indispensible for these type of calculations.

The strain controlled fatigue tests were undertaken on specialised test stands used solely for the purpose of determining LCF material characteristics. The test stands are servo-hydraulically operated and controlled via MTS digital controllers. The hydraulic piston is controlled by the strain signal obtained from a strain gauge based extensometer pressed onto the machined side of the specimen with thin rubber bands, Fig. 1. 


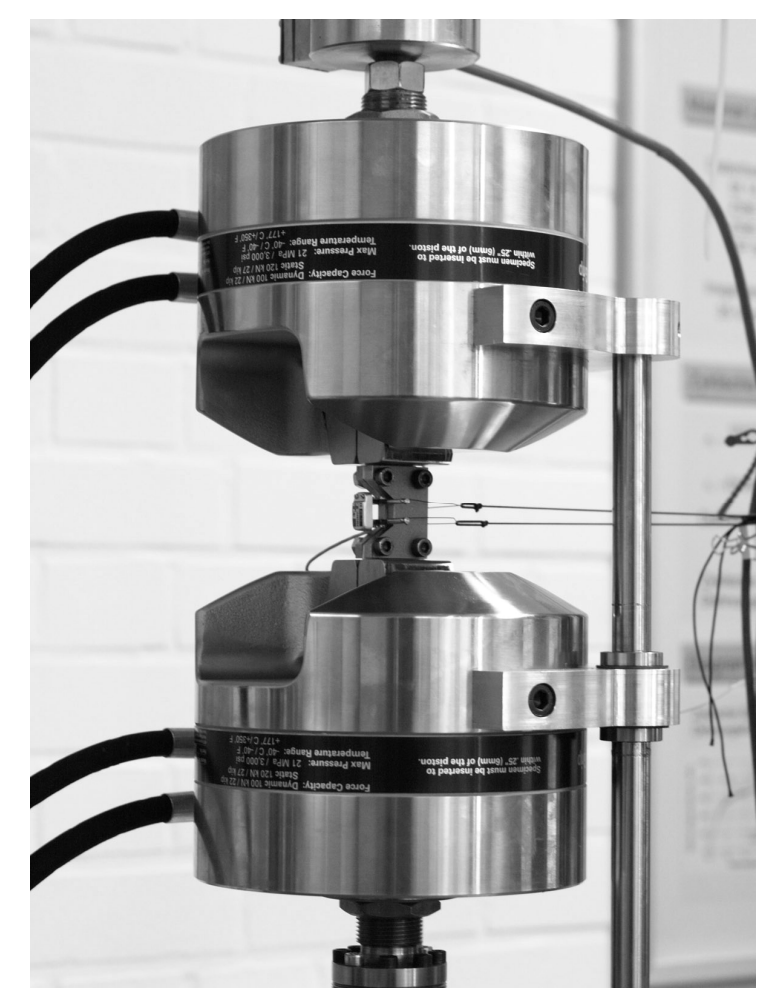

Fig. 1: LCF test stand with mounted specimen and extensometer

Strain and force values, derived from the extensometer and a load cell on the upper crosshead of the test stand, are recorded on a PC using high precision A-D converters for later analysis. The tests were undertaken according to the industry standard SEP1240 [1]. This standard describes the exact procedure to be adhered to when undertaking LCF tests, as well as the specimen geometry, Fig. 2. The main points of the standard describe the exact strain levels the tests are run at and the number of specimens to be used. In this case, the three fixed strain levels of 8,4 and $2 \%$ were run with three specimens each. Then another three specimens were tested at different levels, for this material strain values of over $2 \%$ were needed to achieve safe specimen failure. If specimen failure does not take place within the maximum number of cycles of 1 million, the tests are terminated, the specimen can then not be considered in the evaluation of the experiment. The analysis of the gathered data for the tested specimens was also undertaken as described in SEP1240 using the well known and proven Manson-Coffin and Ramberg-Osgood equations [2,3,4]. The recorded data of each specimen is analysed at the point of half the number of failure cycles. For this one cycle in the specimens fatigue life the maximum strain and stress values are extracted and used for the generation of the strain-life curve and cyclic stress-strain curve along with the number of cycles to failure. According to Ramberg and Osgood the total strain amplitude is the sum of the elastic and plastic strain, the elastic strain being dependant on Young's modulus and the stress amplitude. Therefore the difference between the measure strain the calculated elastic strain is the plastic strain. Put in another way, the plastic strain is the ratio of the stress amplitude to the cyclic hardening coefficient, raised to the power of the reciprocal of the cyclic hardening exponent. The sum of the elastic and plastic strain is the total strain, as measured by the extensometer in the test, Eq. 1:

$$
\varepsilon_{a, t}=\varepsilon_{a, e}+\varepsilon_{a, p}=\left(\frac{\sigma_{a}}{E}\right)+\left(\frac{\sigma_{a}}{K^{\prime}}\right)^{\frac{1}{n^{\prime}}}
$$

A very similar theory is used to describe the total strain in the strain-life curve. Manson-Coffin use different parameters to describe the same physical basis, Eq. 2:

$$
\varepsilon_{a, t}=\varepsilon_{a, e}+\varepsilon_{a, p}=\frac{\sigma_{f}^{\prime}}{E} \cdot(2 N)^{b}+\varepsilon_{f}^{\prime} \cdot(2 N)^{c}
$$


Using compatibility equations, the cyclic material behaviour can be described using four constants, the cyclic stress coefficient $\sigma_{\mathrm{f}}{ }^{6}$, the cyclic stress exponent $b$, the cyclic ductility coefficient $\varepsilon_{\mathrm{f}}{ }^{6}$ and the cyclic strain exponent $c$ as well Young's modulus:

$$
\begin{gathered}
n^{\prime}=\frac{b}{c} \\
K^{\prime}=\frac{\sigma_{f}^{\prime}}{\varepsilon_{f}^{{ }^{\prime}}}
\end{gathered}
$$

If these four previously mentioned parameters have been determined, the cyclic material behaviour has been completely recorded and the cyclic stress-strain curve can be produced by the formulae above (Eq. 3, Eq. 4). The cyclic data from these tests can subsequently be used for fatigue life calculations of various types, as previously mentioned in this paper.

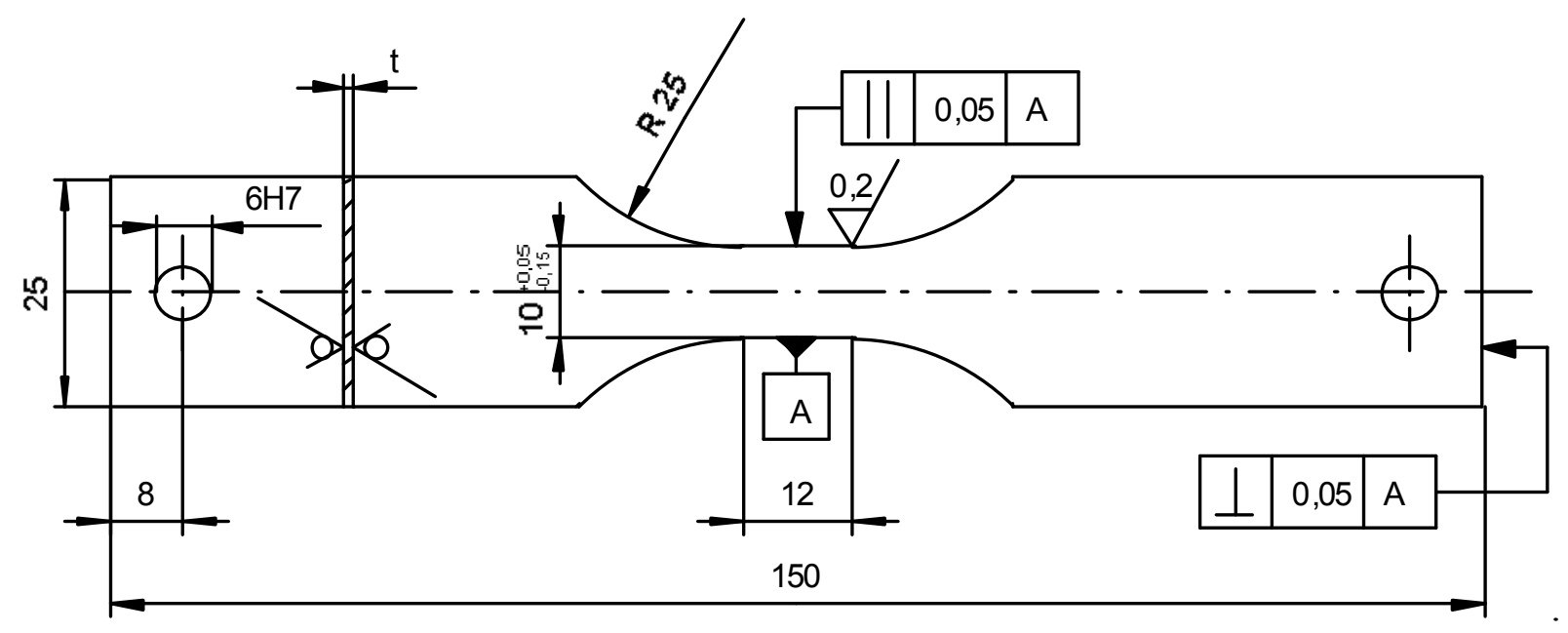

Fig. 2: LCF specimen according to SEP1240

\section{Influence of forming on sheet metals}

The first material strain controlled LCF tests were undertaken on is TRIP780, with a thickness of $1 \mathrm{~mm}$ and zinc coating for corrosion protection purposes. This type of thin sheet metal is a complex three phase steel with a metastable austenitic phase and some martensite forming potential. This means that micro structure changes can take place by diffusion, but also without diffusion. Martensite is formed from residual austenite under mechanical deformation, the energy for the conversion coming from the forming process, or by supercooling. Martensite can only be formed in a certain band of temperatures, the martensite start temperature being in cryogenic regions, the maximum temperature being dependant on the exact chemical composition, but room temperature is still cold enough to form martensite under certain circumstances. In general it can be said that enough energy can be introduced into the material by distortion to allow a safe forming of martensite even well above the martensite start temperature. The transformation is characterised by a change of the crystals' structure due to a cooperative shear motion. This material was developed to combine the advantages of classic deep drawing steels, such as large amounts of uniform elongation and good ductility with low spring back, with high strength properties. It has good potential for dynamically loaded sheet metal structures due to the relative ease of forming whilst retaining very useful strength and fatigue properties.

To compare and classify results of the newer TRIP780, results of previous LCF tests of TRIP700 were available from another research project [6]. Extensive tests were undertaken within this project, including pre-stretched specimens. Another source for fatigue data on this type of material is form the FAT [5] project. 
The test results are unusual for this type of residual-austenite-steel. Both the cyclic stress strain curves and the strain S-N curves are almost identical for each of the pre-stretch states. There is very little difference between the cyclic stress strain curves for $0 \%$ and $5 \%$ pre-stretch over the complete strain band tested. Also, the curve for $10 \%$ pre-stretch is only very slightly higher for strain amplitudes larger than 5\%. These results differ from what was expected and hoped for and do not compare well to other, previous tests of similar material for the state of zero pre-stretch and similar states of pre-stretch. The strain S-N curve shows a similar behaviour for each of the three current test series. In the cycle range from 1.000 to 10.000 .000 the three curves of different pre-stretch levels are near identical, no significant differences in strain can be seen for a given number of life cycles. The effects of pre-stretching are not detectable at all, neither an improvement nor a reduction in fatigue life are apparent. A positive effect of pre-stretching on the stress levels is not apparent, either. Obviously the material has not hardened due to the pre-stretching.

Taking into account the design process of deep drawn thin sheet metal parts, it was to be expected that this type of material with residual austenite and potential for a fair degree of martensite formation would show some form of strain hardening, especially for high degrees of prestretch. For the tested batch of material, this does not seem to be the case, making the idea of using the effect of strengthening local areas using high degrees of forming not practical with the tested material. The effects of pre-stretch are negligible and the differences in the strain S-N curves are partly due to a slight amount of scatter in the test results.

The data of the statically tested materials from Wagener's [5] tests deviates from the test data from the more recent tests. The new batch of TRIP780 has a higher tensile strength and also a higher proof stress, but lower uniform and fracture elongation. These factors also speak for the theory that the tested batch of material was stored in such a way that the forming of martensite previous to the tests taking place was promoted or that the a more recent material composition or manufacturing process has changed the material's characteristics in such a way, that the tensile strength and cyclic stress strain behaviour are higher than for previous production lots while sacrificing the magnitude of uniform elongation and elongation to fracture slightly.

The cyclic test data differs strongly from the data of previously tested TRIP700. The data available was created in the same way as the current data. The specimens were also uniaxialy prestretched in the same way to ensure comparability. The FAT [5] data is for three amounts of prestretch, $0 \%, 10 \%$ and $17 \%$. The cyclic stress-strain curves of the FAT and VDEH [6] for no prestretch (material as delivered) match well, Fig. 3, FAT and VDEH tests indicate a cyclic yield strength of $430 \mathrm{MPa}$ and $419 \mathrm{MPa}$ respectively. Only small deviations are apparent over the whole spectrum of strain amplitude up to $10 \%$. At this amount of strain the stress amplitude is around $520 \mathrm{MPa}$ for these two test series, whereas the current TRIP780 has a stress amplitude of around $630 \mathrm{MPa}$ at the same strain amplitude and much higher cyclic yield stress value of around $550 \mathrm{MPa}$. This increase of $20 \%$ is only matched by the pre-stretched FAT tests of $17 \%$ pre-stretch, the stress reaching almost the levels of the current test series, Fig. 3. Also, the influence of the pre-stretching on the cyclic hardening can clearly be seen. There is a marked interaction between the magnitude of pre-stretching and the improvement in the cyclic stress levels for a given strain across the whole band of strain tested. Here, the work hardening due to the formation of martensite as a result of prestretching has worked as expected, giving a marked increase in stress carrying ability for a given amount of strain, or, seen from the viewpoint of the local strain concept, less strain for a given load stress. The maximum stress values are still slightly lower than for the current batch of material, though.

The strain life curves, show a mixed picture. Comparing the base materials, Fig. 4, again shows a very good consistency of the VDEH and FAT test data without pre-stretch. Also, the current batch of material shows a good match at cycles lower than 10.000. At lower strain levels and cycle numbers of up to 1 million, the bearable strain of the current series of tests is shown to be slightly higher. When looking for similarities of the pre-stretched specimens, only the results from the $10 \%$ pre-stretched FAT data match the current strain S-N curve results. Here the strain amplitudes are very similar over a wide range of cycle numbers, ranging from 10.000 to 1 million. The FAT 
specimens pre-stretched to $17 \%$ and without pre-stretch do not show such a good fatigue life at low stain levels, in fact the number of cycles to failure for the $17 \%$ test series is not better than the result for the series without pre-stretch, indicating that the $10 \%$ series is the optimum for maximum fatigue life with increased stress carrying capability. This result is slightly different to the trends of the current material, here the number of cycles is not affected by the amount of pre-stretch for a given strain amplitude.

The similar test results are not a coincidence, but an indication that the currently tested material shows a high degree of hardening previous to the various stages of pre-stretching undertaken before the LCF tests. This hardening had probably taken place during manufacture; over-ageing may also be a possible explanation. The tested specimen were pre-stretched around six months after the production date of the material, previous storage conditions are unknown, but it is certain that the material was stored within a temperature range of -5 to $+25^{\circ} \mathrm{C}$, without any sudden temperature changes, making the formation of temperature induced martensite unlikely.

Another unusual observation was made during the tests of the pre-stretched specimens concerning the stresses in the specimens during the test. As the tests are strain controlled, the measured stresses in the specimen are usually identical for both tension and compression directions of a cycle, i.e. the material has a symmetrical stress-strain hysteresis about the strain axis. This is indicated by the factor $\mathrm{R}$, which is the ratio of compressive stress to tensile stress for the stabilised hysteresis. Ideally, R equals -1 . In case of the pre-stretched specimens this behaviour was not observed during the tests with low strain amplitudes. In all of the cases where strain amplitudes of smaller than 2,5\%o were chosen, the stresses were not symmetrical, leading to large deviations from the ideal stress ratio of -1 . When higher strain levels were set for tests, this effect slowly disappeared, until the ratio of $\mathrm{R}=-1$ was again reached for strain levels of $6 \%$ and above.

The residual stresses in pre-stretched specimens seem to be very high. Low strain amplitudes of under $2.5 \%$ do not reduce residual stresses in the specimens, tensile loads in the direction of the pre-stretch are much higher than for compressive loads. This effect can be explained with the very low plastic deformation during tests with strain amplitudes of around $2 \%$. The majority of elongation at these strain levels is elastic, thereby not leading to a reduction of the residual stresses caused by the pre-stretching. When higher strain levels are chosen, the plastic elongation of the specimen also increases, slowly reducing the residual stresses in the material until, after a few dozen cycles, the residual stresses are almost zero. This is known as cyclic creeping/relaxation.

The thin sheet metal TRIP780 tested in this project showed a behaviour not known from previous experience with this material. In its delivered state, the stress levels for a given strain level were very high compared to previous tests of nominally the same material. Gains of up to $20 \%$ higher bearable stress for a given strain amplitude compared to other tests were seen, the static tensile test results are also better concerning the tensile strength. On the other hand, pre-stretching the current material had no effect at all on the strain S-N curve and therefore no effect on the fatigue life behaviour. No advantages can be gained by pre-stretching this material concerning its cyclic fatigue behaviour. This characteristic is very unusual for multi phase austenitic steels. Compared to test results from previous research, the differences concerning the changes of cyclic behaviour can be clearly seen. FAT and VDEH results show that other batches of TRIP700 show a considerable change in their cyclic behaviour when subjected to a similar amount of pre-stretching. The cause for the absence of these effects in the current batch of TRIP780 can only be speculated upon and are subject of further research. A metallurgic analysis is of special interest to determine why the current lot of material shows such different behaviour. The inclusion low cycle fatigue test results into fatigue life calculation concepts must be viewed critically with regard to these results. Obviously a nominally identical type of metal sheet can have strongly varying mechanical properties concerning both static and cyclic characteristics. These variations must be taken into account when including material data in fatigue life calculation concepts. It seems advisable to undertake tests on exactly the same material proposed for the structure being optimised to ensure any fatigue life calculations are based on reliable data for the material at hand. 


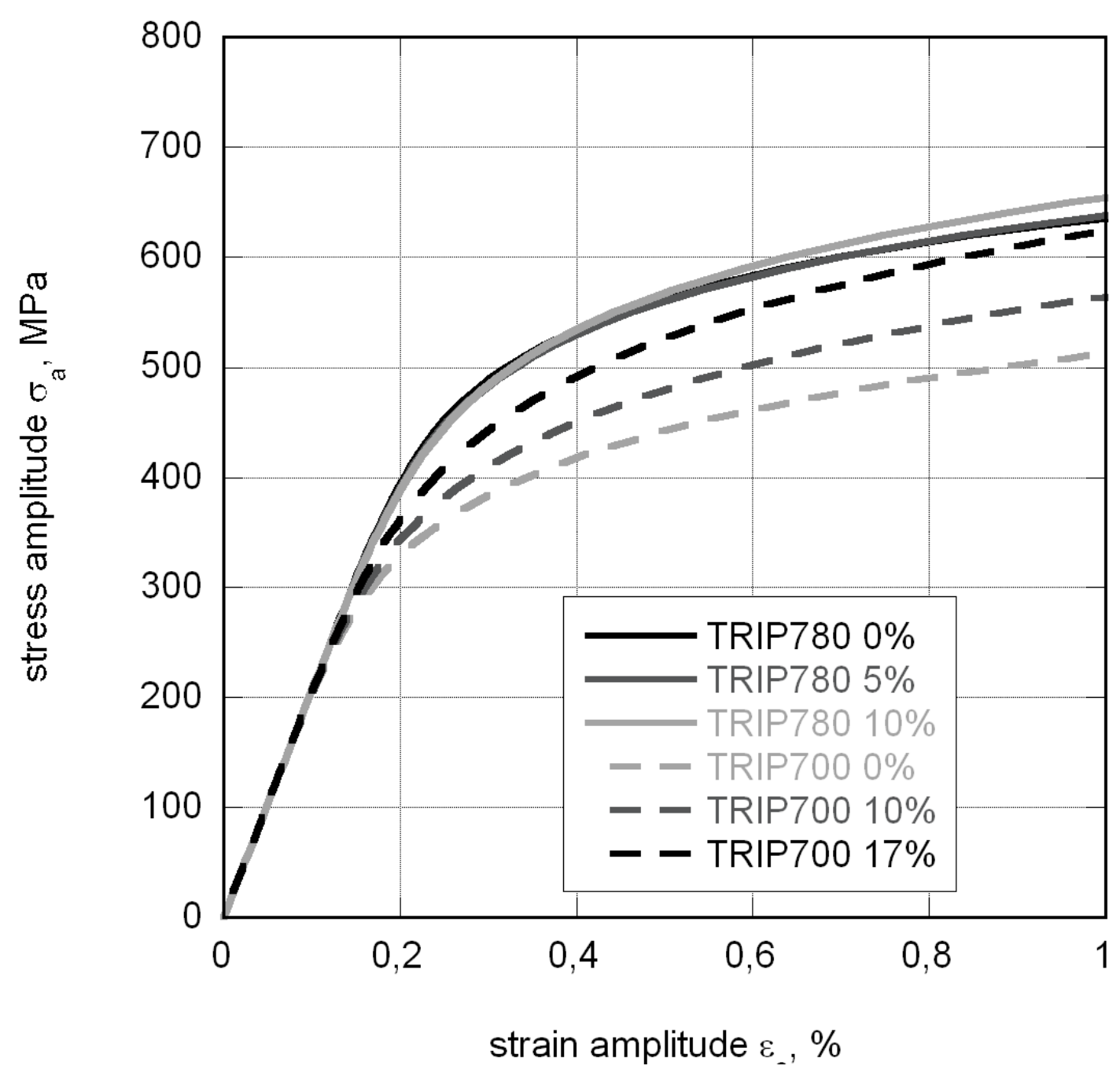

Fig. 3: cyclic stress-strain curves for TRIP materials at various amounts of pre-stretch 


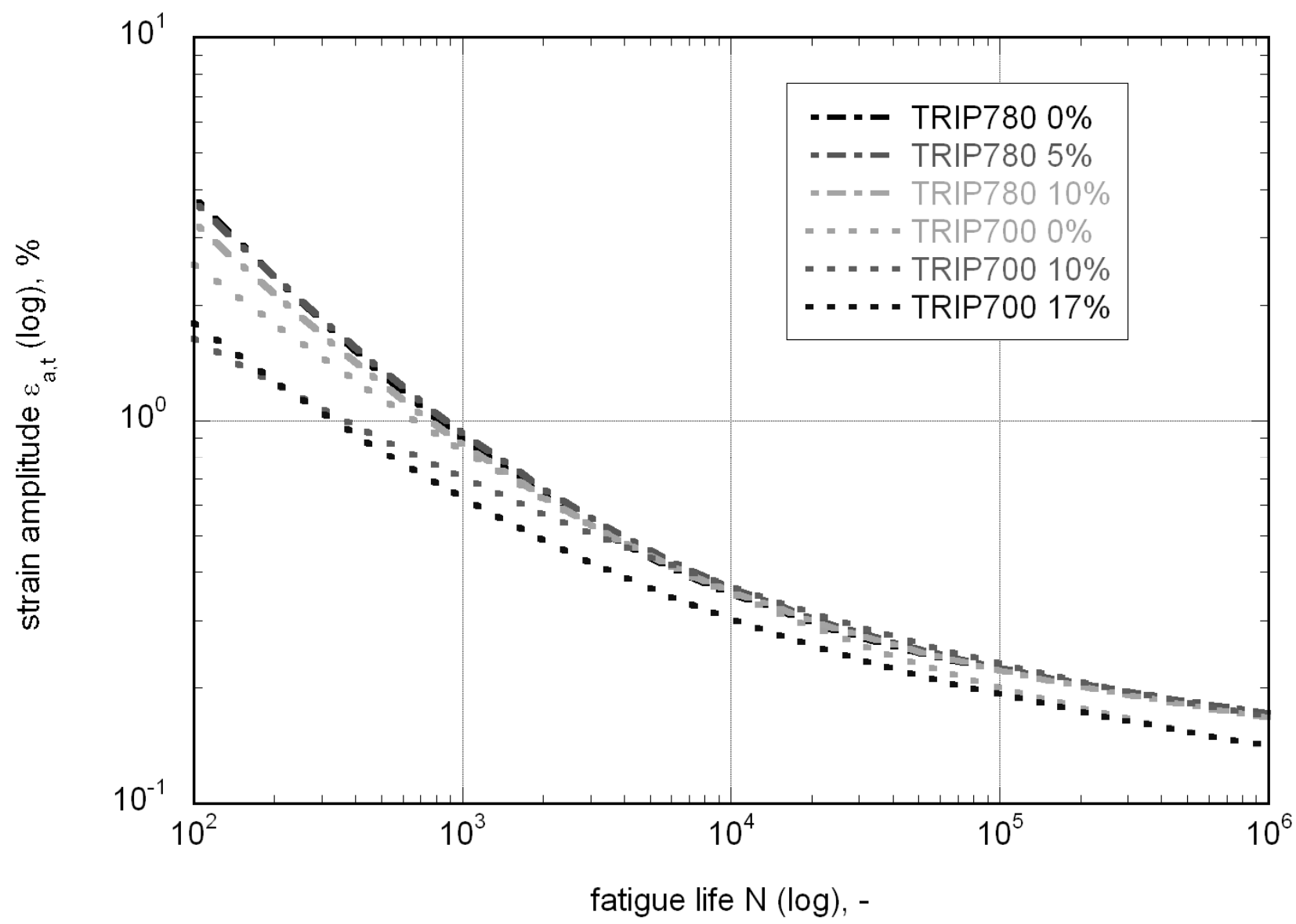

Fig. 4: strain-life curves for TRIP materials at various amounts of pre-stretch

Table 1: Characteristic values for the elastic and plastic behaviour from the tensile test

\begin{tabular}{|l|c|c|c|c|}
\hline material & tensile & yield & uniform & total \\
& Strength & Strength & elongation & elongation \\
& $\mathrm{R}_{\mathrm{m}}$ & $\mathrm{R}_{\mathrm{p} 0,2}$ & $\mathrm{~A}_{\mathrm{g}}$ & $\mathrm{A}_{80}$ \\
& $\mathrm{MPa}$ & $\mathrm{MPa}$ & $\%$ & $\%$ \\
\hline TRIP780 & 807 & 466 & 19,2 & 26,7 \\
\hline TRIP700Z & 706 & 420 & 20,0 & 25,1 \\
\hline TRIP700 & 755 & 439 & 24,6 & 30,6 \\
\hline
\end{tabular}

Table 2: Characteristic values for the cyclic behaviour from TRIP 700 as received

\begin{tabular}{|c|c|c|c|c|c|c|c|c|}
\hline \multirow[b]{2}{*}{ Material } & \multicolumn{3}{|c|}{ cyclic stress-strain curve } & \multicolumn{5}{|c|}{ strain SN curve } \\
\hline & $\begin{array}{c}\text { cyclic } \\
\text { hardening } \\
\text { coefficient } \\
\mathrm{K}^{\prime} \\
\mathrm{MPa}\end{array}$ & $\begin{array}{c}\text { cyclic strain } \\
\text { hardening } \\
\text { exponent } \\
\text { n' }^{\prime} \\
-\end{array}$ & $\begin{array}{c}\text { cyclic } \\
\text { Yield } \\
\text { Strength } \\
\mathrm{R}_{\mathrm{p} 0,2^{\prime}} \\
\mathrm{MPa}\end{array}$ & $\begin{array}{c}\text { cyclic } \\
\text { strength } \\
\text { coefficient } \\
\sigma_{\mathrm{f}}^{\prime} \\
\mathrm{MPa}\end{array}$ & $\begin{array}{c}\text { cyclic } \\
\text { strength } \\
\text { exponent } \\
\text { b } \\
-\end{array}$ & $\begin{array}{c}\text { cyclic } \\
\text { ductility } \\
\text { coefficient } \\
\varepsilon_{\mathrm{f}}^{\prime} \\
-\end{array}$ & $\begin{array}{c}\text { cyclic } \\
\text { ductility } \\
\text { exponent } \\
\text { c } \\
-\end{array}$ & $\begin{array}{c}\text { young's } \\
\text { modulus } \\
\text { E } \\
\mathrm{GPa}\end{array}$ \\
\hline TRIP780 & 1105 & 0,1109 & 554 & 1193 & $-0,0849$ & 2,0012 & $-0,7658$ & 206 \\
\hline TRIP700Z & 1002 & 0,1344 & 430 & 1066 & $-0,0938$ & 1,5807 & $-0,6477$ & 206 \\
\hline TRIP700 & 1085 & 0,1532 & 419 & 972 & $-0,0889$ & 0,4882 & $-0,5803$ & 206 \\
\hline
\end{tabular}


Table 3: Characteristic values for the cyclic behaviour from TRIP 700 pre-stretched

\begin{tabular}{|c|c|c|c|c|c|c|c|c|c|}
\hline \multirow{3}{*}{ material } & \multirow{3}{*}{ pre-stretching } & \multicolumn{3}{|c|}{ cyclic stress-strain curve } & \multicolumn{5}{|c|}{ strain SN curve } \\
\hline & & $\begin{array}{c}\text { cyclic } \\
\text { hardening } \\
\text { coefficient }\end{array}$ & $\begin{array}{c}\text { cyclic strain } \\
\text { hardening } \\
\text { exponent }\end{array}$ & $\begin{array}{c}\text { cyclic yield } \\
\text { Strength }\end{array}$ & $\begin{array}{c}\text { cyclic } \\
\text { strength } \\
\text { coefficient }\end{array}$ & $\begin{array}{c}\text { cyclic } \\
\text { strength } \\
\text { exponent }\end{array}$ & $\begin{array}{c}\text { cyclic } \\
\text { ductility } \\
\text { coefficient }\end{array}$ & $\begin{array}{c}\text { cyclic } \\
\text { ductility } \\
\text { exponent }\end{array}$ & $\begin{array}{l}\text { young's } \\
\text { modulus }\end{array}$ \\
\hline & & $\begin{array}{c}\mathrm{K}^{\prime} \\
\mathrm{MPa} \\
\end{array}$ & $\begin{array}{c}\mathrm{n}^{\prime} \\
- \\
\end{array}$ & $\begin{array}{l}\mathrm{R}_{\mathrm{p} 0,2^{\prime}} \\
\mathrm{MPa} \\
\end{array}$ & $\begin{array}{c}\sigma_{\mathrm{f}}^{\prime} \\
\mathrm{MPa}\end{array}$ & $\begin{array}{l}\mathrm{b} \\
-\end{array}$ & $\begin{array}{c}\varepsilon_{\mathrm{f}}^{\prime} \\
-\end{array}$ & $\begin{array}{l}\mathrm{c} \\
- \\
\end{array}$ & $\begin{array}{c}\mathrm{E} \\
\mathrm{GPa}\end{array}$ \\
\hline \multirow[t]{3}{*}{ TRIP780 } & 0 & 1105 & 0,1109 & 554 & 1193 & $-0,0849$ & 2,0012 & $-0,7658$ & 206 \\
\hline & 5 & 1148 & 0,1179 & 552 & 1220 & $-0,0868$ & 1,6663 & $-0,7358$ & 206 \\
\hline & 10 & 1241 & 0,1283 & 559 & 1287 & $-0,0924$ & 1,3283 & $-0,7198$ & 206 \\
\hline \multirow[t]{3}{*}{ TRIP700 } & 0 & 1085 & 0,1532 & 419 & 972 & $-0,0889$ & 0,4882 & $-0,5803$ & 206 \\
\hline & 10 & 1259 & 0,1629 & 458 & 933 & $-0,0761$ & 0,1587 & $-0,4675$ & 206 \\
\hline & 17 & 1405 & 0,1633 & 509 & 1195 & $-0,0999$ & 0,3699 & $-0,6117$ & 206 \\
\hline
\end{tabular}

\section{Pre-stretched austenitic steels under cyclic loading}

The strengthening potential of steel sheets with residual austenitic phases was shown under cyclic loading in the preceding section of this paper. Making use of the strengthening potential of the austenitic phase requires a number of conditions to be met, one of them being the ability of the phase to form martensite as a result of deformation. This is the case for true austenitic steels with a metastable austenitic phase, such as the material grade 1.4301, 1.4404 and 1.4571. In these materials the metastable austenitic phase is easily transformed into a martensitic phase, the transformation takes place either in the form of $\gamma \cdot \rightarrow \varepsilon$ or $\gamma \rightarrow \alpha^{\prime}$. The degree of transformation depends on various influences, the main ones are the degree of forming, as a plastic strain, and the temperature at which the forming takes place. Lower temperatures favour the evolution of martensite [8], whereas the forming of martensite can be completely inhibited at temperatures of above $100{ }^{\circ} \mathrm{C}$. The effects of these influences were experimentally examined in cooperation with part project A1, which formed various geometries into test specimens of the 1.4301 material for cyclic testing. At first though, a general investigation of the forming influence at room temperature for the three mentioned materials was undertaken.

Preliminary tensile tests showed a uniform elongation of at least $45 \%$ for all three tested materials, Table 4. This large uniaxial forming potential can be used to make complex deep drawn parts without problems of tearing in areas of high deformation. The cyclic parameters were determined by undertaking strain controlled low cycle fatigue tests under identical conditions to the tests described above for the TRIP780 material, Table 5. Furthermore, Incremental Step Tests (IST) [7] were also examined to compare the cyclic hardening behaviour under loads similar to real life loads, Table 7.

Table 4: Tensile test results of austenitic steels

\begin{tabular}{|c|c|c|c|c|}
\hline material & $\begin{array}{l}\text { tensile Strength } \\
\qquad \mathrm{R}_{\mathrm{m}} \\
\mathrm{MPa}\end{array}$ & $\begin{array}{l}\text { yield Strength } \\
\qquad \mathrm{R}_{\mathrm{p} 0,2} \\
\mathrm{MPa}\end{array}$ & $\begin{array}{c}\text { uniform } \\
\text { elongation } \\
\mathrm{A}_{\mathrm{g}} \\
\% \\
\%\end{array}$ & $\begin{array}{l}\text { total elongation } \\
\qquad \begin{array}{c}\mathrm{A}_{80} \\
\%\end{array} \\
\end{array}$ \\
\hline 1.4301 & 684 & 327 & 50,4 & 59,5 \\
\hline 1.4404 & 636 & 323 & 50,5 & 60,9 \\
\hline 1.4571 & 635 & 315 & 48,9 & 56,2 \\
\hline
\end{tabular}


Table 5: cyclic parameters of single load step strain controlled LCF tests

\begin{tabular}{|c|c|c|c|c|c|c|c|c|}
\hline \multirow[b]{2}{*}{ Material } & \multicolumn{3}{|c|}{ cyclic stress-strain curve } & \multicolumn{5}{|c|}{ strain SN curve } \\
\hline & $\begin{array}{c}\text { cyclic } \\
\text { hardening } \\
\text { coefficient } \\
\mathrm{K}^{\prime} \\
\mathrm{MPa} \\
\end{array}$ & $\begin{array}{c}\text { cyclic strain } \\
\text { hardening } \\
\text { exponent } \\
\text { n' }^{\prime} \\
- \\
\end{array}$ & $\begin{array}{l}\text { cyclic } \\
\text { Yield } \\
\text { Strength } \\
\mathrm{R}_{\mathrm{p} 0,2^{\prime}} \\
\mathrm{MPa} \\
\end{array}$ & $\begin{array}{c}\text { cyclic } \\
\text { strength } \\
\text { coefficient } \\
\sigma_{\mathrm{f}}^{\prime} \\
\mathrm{MPa} \\
\end{array}$ & $\begin{array}{c}\text { cyclic } \\
\text { strength } \\
\text { exponent } \\
\text { b } \\
- \\
\end{array}$ & $\begin{array}{c}\text { cyclic } \\
\text { ductility } \\
\text { coefficient } \\
\varepsilon_{\mathrm{f}}^{\prime} \\
- \\
\end{array}$ & $\begin{array}{c}\text { cyclic } \\
\text { ductility } \\
\text { exponent } \\
\text { c } \\
- \\
\end{array}$ & $\begin{array}{c}\text { young's } \\
\text { modulus } \\
\text { E } \\
\mathrm{GPa} \\
\end{array}$ \\
\hline 1.4301 & 1564 & 0,2603 & 310 & 849 & $-0,0930$ & 0,0956 & $-0,3573$ & 206 \\
\hline 1.4404 & 1197 & 0,2011 & 343 & 870 & $-0,0899$ & 0,2046 & $-0,4470$ & 206 \\
\hline 1.4571 & 1011 & 0,1514 & 395 & 906 & $-0,0852$ & 0,4832 & $-0,5628$ & 206 \\
\hline
\end{tabular}

Table 6: cyclic parameters of single load step strain controlled LCF test with pre-stretching

\begin{tabular}{|c|c|c|c|c|c|c|c|c|c|}
\hline \multirow{3}{*}{ material } & \multirow{3}{*}{ pre-stretching } & \multicolumn{3}{|c|}{ cyclic stress-strain curve } & \multicolumn{5}{|c|}{ strain SN curve } \\
\hline & & $\begin{array}{c}\text { cyclic } \\
\text { hardening } \\
\text { coefficient }\end{array}$ & $\begin{array}{c}\text { cyclic strain } \\
\text { hardening } \\
\text { exponent }\end{array}$ & $\begin{array}{l}\text { cyclic yield } \\
\text { Strength }\end{array}$ & $\begin{array}{c}\text { cyclic } \\
\text { strength } \\
\text { coefficient }\end{array}$ & $\begin{array}{c}\text { cyclic } \\
\text { strength } \\
\text { exponent }\end{array}$ & $\begin{array}{c}\text { cyclic } \\
\text { ductility } \\
\text { coefficient }\end{array}$ & $\begin{array}{c}\text { cyclic } \\
\text { ductility } \\
\text { exponent }\end{array}$ & $\begin{array}{l}\text { young's } \\
\text { modulus }\end{array}$ \\
\hline & & $\begin{array}{c}\mathrm{K}^{\prime} \\
\mathrm{MPa}\end{array}$ & $\begin{array}{l}\mathrm{n}^{\prime} \\
-\end{array}$ & $\begin{array}{l}\mathrm{R}_{\mathrm{p} 0,2^{\prime}} \\
\mathrm{MPa}\end{array}$ & $\begin{array}{l}\sigma_{\mathrm{f}}^{\prime} \\
\mathrm{MPa}\end{array}$ & $\begin{array}{l}b \\
-\end{array}$ & $\begin{array}{c}\varepsilon_{\mathrm{f}}^{\prime} \\
-\end{array}$ & $\begin{array}{l}\mathrm{c} \\
-\end{array}$ & $\begin{array}{c}\mathrm{E} \\
\mathrm{GPa}\end{array}$ \\
\hline \multirow[t]{4}{*}{1.4301} & 0 & 1564 & 0,2603 & 310 & 849 & $-0,0930$ & 0,0956 & $-0,3573$ & 206 \\
\hline & 5 & 1307 & 0,1972 & 384 & 928 & $-0,0853$ & 0,1764 & $-0,4327$ & 206 \\
\hline & 10 & 1246 & 0,1703 & 433 & 851 & $-0,0661$ & 0,1062 & $-0,3884$ & 206 \\
\hline & 15 & 1262 & 0,1547 & 483 & 973 & $-0,0724$ & 0,1859 & $-0,4676$ & 206 \\
\hline \multirow[t]{4}{*}{1.4404} & 0 & 1197 & 0,2011 & 343 & 870 & $-0,0899$ & 0,2046 & $-0,4470$ & 206 \\
\hline & 5 & 943 & 0,1370 & 403 & 789 & $-0,0660$ & 0,2719 & $-0,4816$ & 206 \\
\hline & 10 & 873 & 0,1228 & 433 & 752 & $-0,0545$ & 0,2656 & $-0,4835$ & 206 \\
\hline & 15 & 879 & 0,0947 & 488 & 791 & $-0,0509$ & 0,3317 & $-0,5377$ & 206 \\
\hline \multirow[t]{3}{*}{1.4571} & 0 & 1011 & 0,1514 & 395 & 906 & $-0,0852$ & 0,4832 & $-0,5628$ & 206 \\
\hline & 10 & 951 & 0,1192 & 453 & 835 & $-0,0639$ & 0,3376 & $-0,5363$ & 206 \\
\hline & 15 & 874 & 0,0862 & 512 & 896 & $-0,0612$ & 1,3290 & $-0,7105$ & 206 \\
\hline
\end{tabular}

Table 7: cyclic parameters of Incremental Step Tests with pre-stretching

\begin{tabular}{|c|c|c|c|c|}
\hline \multirow{3}{*}{ material } & \multirow[b]{2}{*}{ pre-stretching } & \multicolumn{3}{|c|}{ cyclic stress-strain curve } \\
\hline & & $\begin{array}{l}\text { cyclic hardening } \\
\text { coefficient }\end{array}$ & $\begin{array}{c}\text { cyclic strain } \\
\text { hardening exponent }\end{array}$ & $\begin{array}{l}\text { cyclic yield } \\
\text { Strength }\end{array}$ \\
\hline & $\%$ & $\begin{array}{c}\mathrm{K}^{\prime} \\
\mathrm{MPa}\end{array}$ & $\begin{array}{l}\mathrm{n}^{\prime} \\
-\end{array}$ & $\begin{array}{l}\mathrm{R}_{\mathrm{p} 0,2^{\prime}} \\
\mathrm{MPa}\end{array}$ \\
\hline \multirow[t]{6}{*}{1.4301} & 0 & 887 & 0,1446 & 353 \\
\hline & 5 & 903 & 0,1305 & 401 \\
\hline & 10 & 1123 & 0,1572 & 422 \\
\hline & 15 & 1284 & 0,1654 & 459 \\
\hline & 20 & 1464 & 0,1699 & 509 \\
\hline & 25 & 1542 & 0,1615 & 565 \\
\hline \multirow[t]{4}{*}{1.4404} & 0 & 741 & 0,1139 & 361 \\
\hline & 5 & 782 & 0,1098 & 395 \\
\hline & 10 & 902 & 0,1248 & 416 \\
\hline & 15 & 950 & 0,1158 & 462 \\
\hline \multirow[t]{3}{*}{1.4571} & 0 & 729 & 0,0943 & 406 \\
\hline & 10 & 821 & 0,0881 & 475 \\
\hline & 15 & 842 & 0,0865 & 492 \\
\hline
\end{tabular}


The Incremental Step Test loads the specimen in a series of 40 increasing strain steps, before decreasing the strain steps back to zero in the same number of steps, in an endless repetition of blocks, Fig. 5. This constant variation of loads throughout the test is a much better representation of true life loads, thereby giving a good indication of the material's behaviour under service conditions. Also, a complete stress-strain curve can be derived from just one specimen test, rather than twelve single load step strain controlled tests as in the SEP1240 testing procedure. In this case, the maximum strain amplitude during the Incremental Step Test was set to $8 \%$, this being the identical maximum value to single load step tests also undertaken. The setting of comparable maximum strain levels is important to allow the stress-strain curves derived from the different experiments to be compared. Differing levels of maximum strain might lead to different levels of work hardening, making the comparison of influences on the progression of the stress levels difficult.

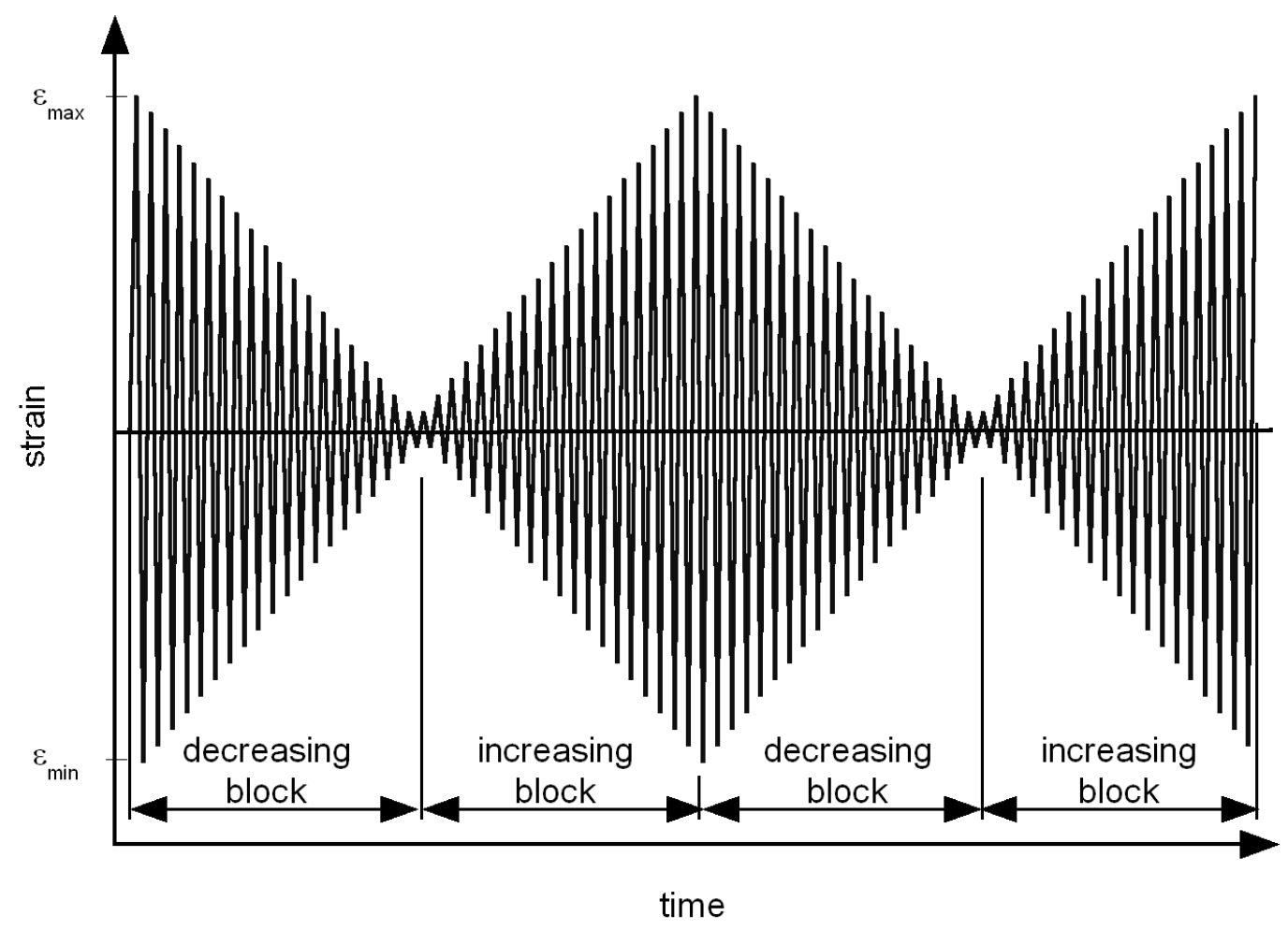

Fig. 5: plot of strain amplitude over time for Incremental Step Test

Various amounts of pre-stretch were applied to the specimens before conducting a complete test series of strain controlled experiments in single load step testing as well as using Incremental Step Tests. The forming was set by uniaxial stretching in a tensile testing machine up to a specific, predetermined amount of plastic deformation. The strain levels, next to the state of delivery, were $5 \%, 10 \%, 15 \%$ for the single load step tests, additionally $20 \%, 25 \%$ and $30 \%$ of pre-stretch were set into the specimens for the Incremental Step Tests. These uniaxial strain values were converted into a more universal measure of deformation by calculating the equivalent degree of forming $\varphi_{\mathrm{v}}$ according to Eq. 5 and Eq. 6. The direction of the main deformation is of no consequence to the hardening behaviour, the equivalent degree of forming is the influential factor for the following considerations. A Finite Element deep drawing simulation will show the equivalent deformation as a result, making the conversion necessary to allow a comparison of data. The various states of forming in a real deep drawn part are very complex and too numerous to simulate experimentally using specimen, making this abstraction necessary.

$$
\varphi_{1}=\ln \frac{L_{1}}{L_{0}}
$$




$$
\varphi_{V}=\sqrt{\frac{2}{3}\left(\varphi_{1}^{2}+\varphi_{2}^{2}+\varphi_{3}^{2}\right)}
$$

The results of the strain controlled test show a strong correlation of the degree of forming to an improved cyclic strength, Table 6 and Table 7. In all cases of analysed forming by uniaxial prestretching the specimens displayed an increase of the stress levels of the cyclic stress-strain curves. This effect is exemplarily shown in Fig. 6. The complete cyclic stress-strain curve is shifted upwards towards higher stress levels, the cyclic yield strength is increased from $310 \mathrm{MPa}$ to $433 \mathrm{MPa}$ due to the pre-stretching. This considerable increase of cyclic strength is lower than that indicated by the static tests, shown as dashed thin lines in the graph, but still considerable and of great influence for any ensuing fatigue life calculations. The cyclic strain-life curves, Fig. 7, for the same forming states are also slightly affected by the preceding forming, although the influence is not quite as pronounced as in the stress-strain curve. A slight benefit of forming can be seen in the increase in bearable strain amplitude for load cycles larger than $10^{5}$, at strain amplitudes resulting in a lower fatigue life the two curves are virtually identical. However, most parts and machines are designed for fatigue life cycles larger than $10^{6}$ making the increased fatigue life due to forming a worthwhile proposition, especially when seen in combination with the corresponding stress-strain curves.

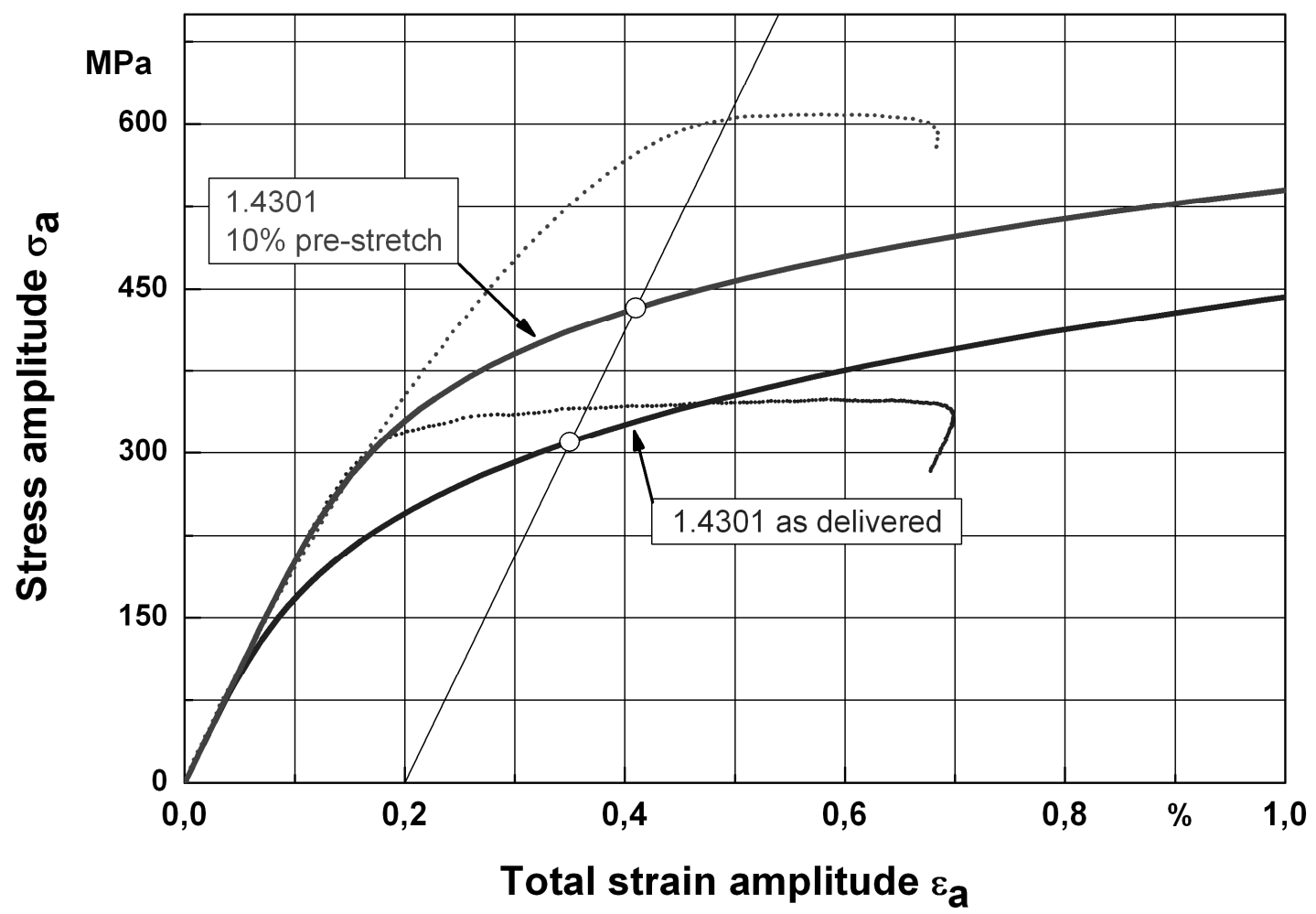

Fig. 6: cyclic stress-strain curve for 1.4301 in state as delivered and for $10 \%$ pre-stretch 


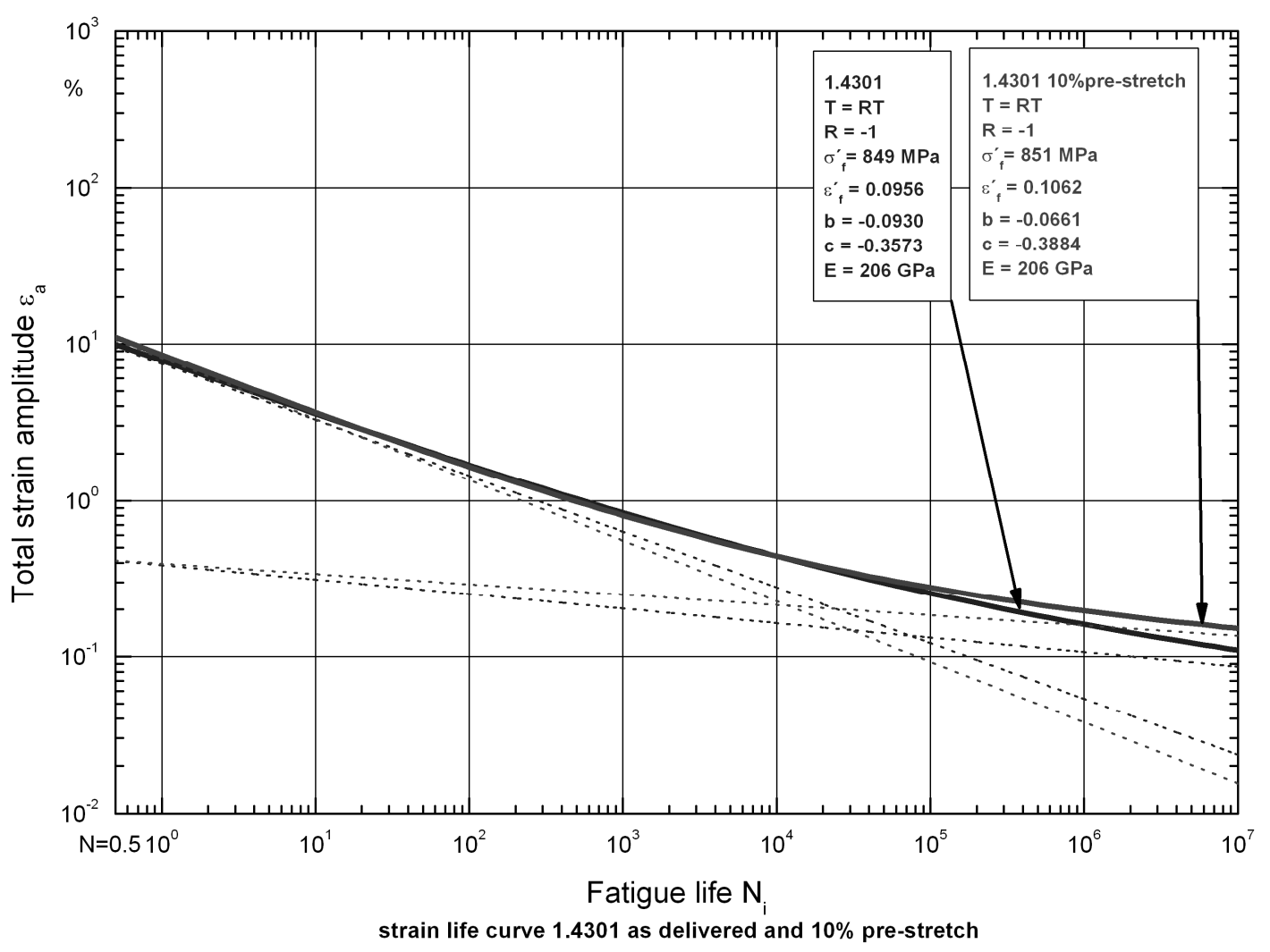

Fig. 7: Strain-life curve for 1.4301 in state of delivery and for $10 \%$ pre-stretch

Fig. 8 shows stress-strain curves for the material 1.4301 in various states of forming ranging from the state of delivery to $25 \%$ pre-stretch, or a forming equivalent of $\varphi_{v}=0,223$. The strong increase of the cyclic strength due to forming can clearly be seen, the cyclic stress-strain curves are shifted upwards over the whole range of strain amplitudes plotted. The basic cyclic yield strength of $364 \mathrm{MPa}$ is increased to a value of $565 \mathrm{MPa}$ as a result of forming, meaning an increase of 55\% over the state of delivery. The strengthening of the material follows an almost linear pattern in the range of pre-stretching investigated in this paper, the forming of hard martensitic phases seems to be proportional to the rate of strain imposed on the specimens previous to testing. This effect will be more closely investigated in a following section of this paper. 


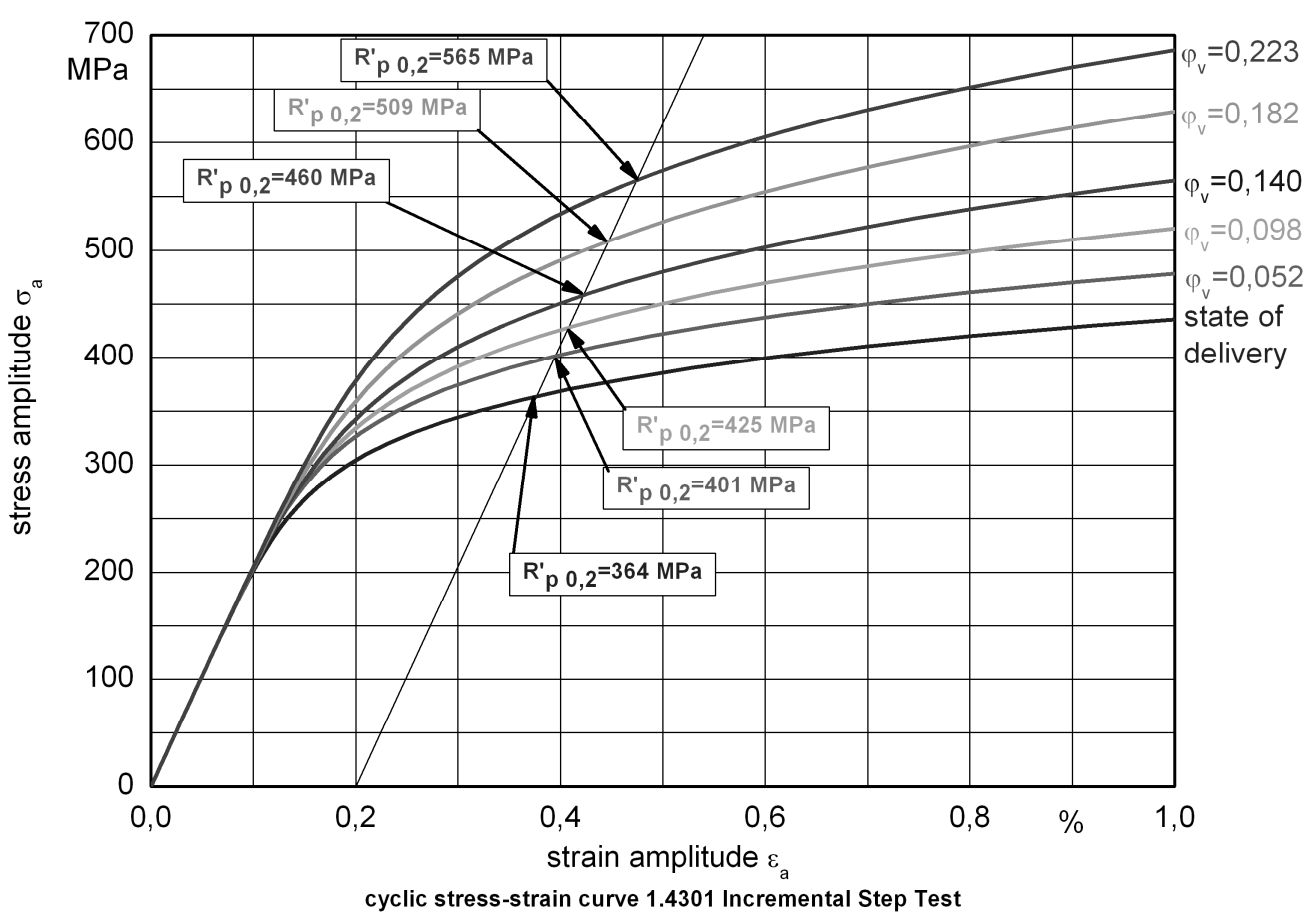

Fig. 8: Stress-strain curves for material 1.4301 for various amount of forming

The described influences of forming on the cyclic behaviour of austenitic steels was also examined for further materials, a small excerpt of which shall be shown now exemplarily for the material 1.4404. The material 1.4571 shows a similar behaviour and will not be looked into in detail. Again, single load step and Incremental Step Tests were undertaken to characterise the cyclic parameters of this material. The resulting stress-strain (Fig. 9) and strain-life (Fig. 10) curves show a very similar dependency of their progression as the curves for the material 1.4301. There is a marked influence of forming on the stress levels the material resists for a given strain, greater levels of forming lead to a large increase of cyclic strength. The cyclic yield strength for example increases from $343 \mathrm{MPa}$ in the state of delivery to $488 \mathrm{MPa}$ when pre-stretched by $15 \%$ uniaxialy, an increase of $42 \%$. The cyclic strain-life curves show a similar tendency to those for the 1.4301 material. For life cycles smaller than $10^{4}$ the curves of the delivery state and pre-stretched material are virtually identical. At higher life cycles the pre-stretched material shows a significant improvement in fatigue resistance compared to the non pre-stretched material. The combination of higher fatigue life at a given strain amplitude and the marked increase of the stress-strain curve show the clear benefit for fatigue life when pre-stretching or other types of forming are applied to this material. 


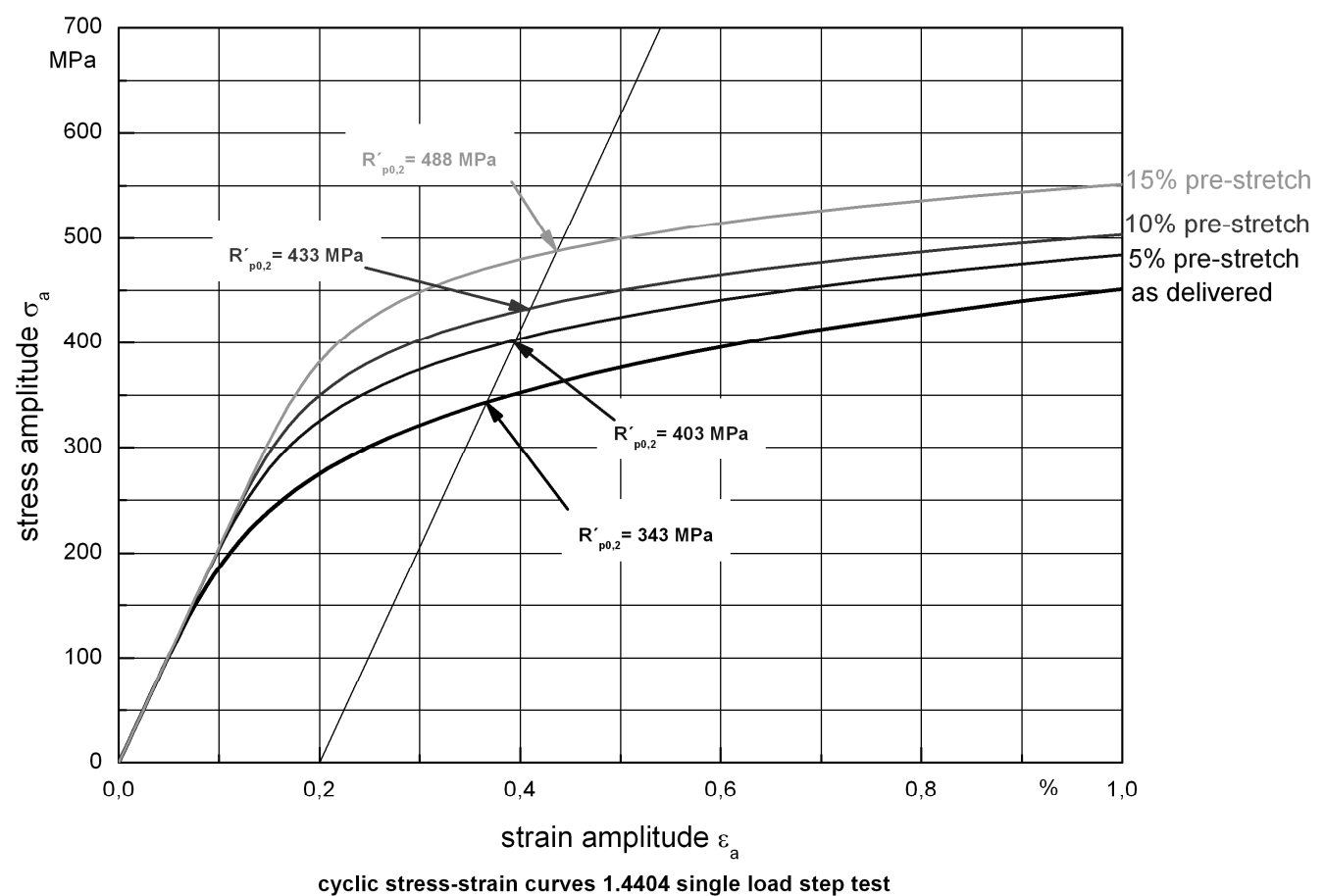

Fig. 9: cyclic stress-strain curves for material 1.4404 in various amounts of pre-stretch

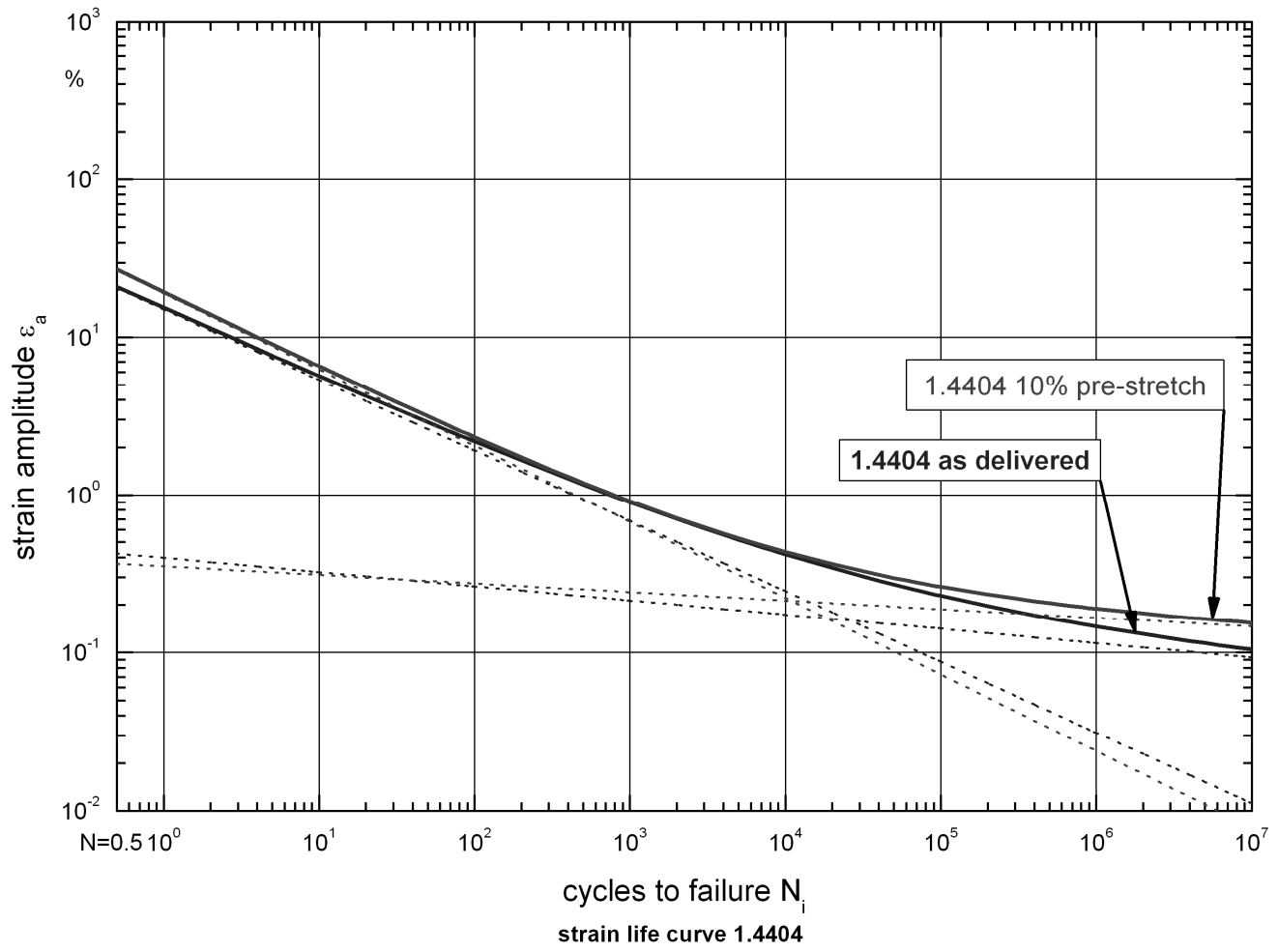

Fig. 10: Strain-life curve for 1.4404 in state of delivery and for $10 \%$ pre-stretch

As the available materials were tested under single load step strain as well as using variable strain amplitudes in the Incremental Step Tests, the influence of operating-like loads on the progression of the stress-strain curve were analysed for a number of different states of pre-stretching. A direct comparison of the stress-strain curves for the material 1.4301 in its' state of delivery is shown in Fig. 11. The stress-strain curve derived form an Incremental Step Test is of a different shape and 
placement in the diagram than the stress-strain curve resulting from single load step tests. The curves start to differ at strain amplitudes above 1\%o and run back together at strain amplitudes of $10 \%$. In the range of strain amplitudes between these two limits, the stress-strain curve of the Incremental Step Test is significantly higher than the single load step curve. This effect is caused by the work hardening of the material due to the high strain amplitudes imposed on the material during an Incremental Step Test. Here, the curve is calculated from experimental points where the material is subjected to a recurring maximum strain of $8 \%$ o during the whole test, whereas the curve for the single load step test is drawn through measured points obtained during testing with strain amplitudes of exactly the magnitude of the point in the curve. This fundamental difference between the two test loads results in the material work hardening during the high strain peaks in the Incremental Step Test, which in turn shifts the complete stress amplitude for a given strain upwards towards higher stress values. This effect does not occur during single load step tests, the material does not work harden due to high strain amplitudes, the resulting stresses are lower. This also explains why the two curves run together at higher strain amplitudes. As the maximum strain amplitudes approach each other, similar amounts of work hardening take place, resulting in similar stress amplitudes for similar strain amplitudes.

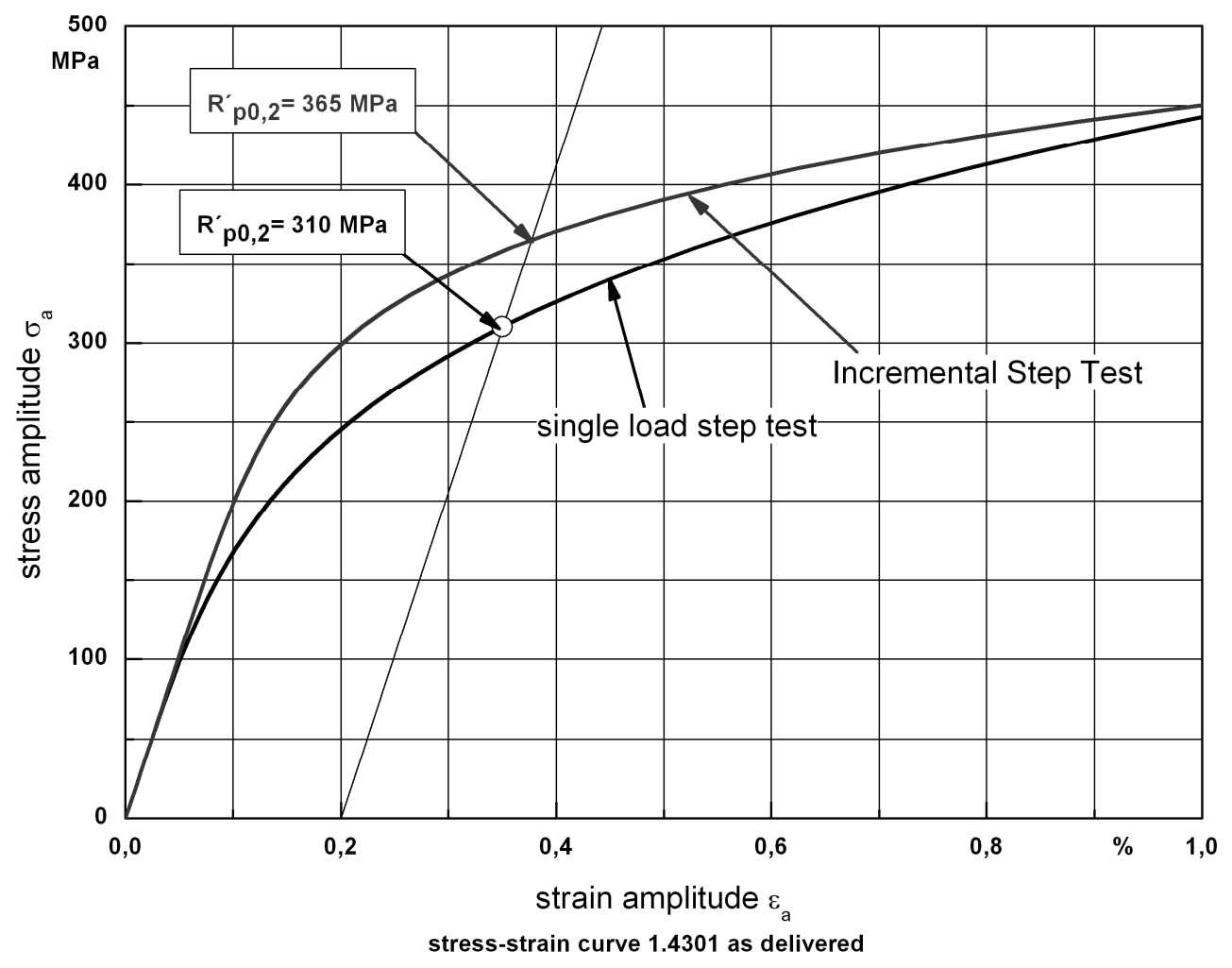

Fig. 11: cyclic stress-strain curves for material 1.4301, comparison of single load step and IST, state as delivered 


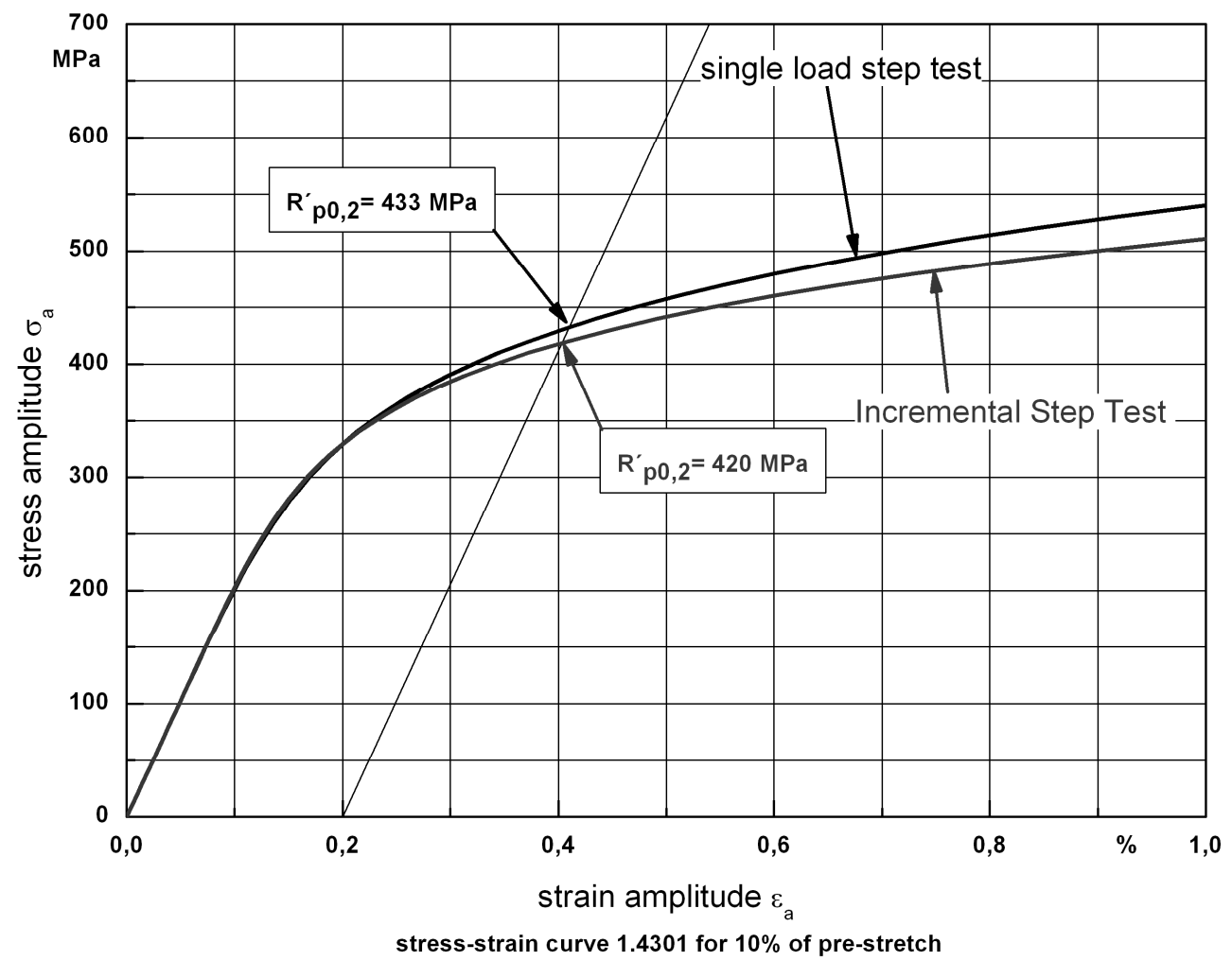

Fig. 12: stress-strain curves for material 1.4301, comparison of single load step and IST, 10\% prestretch

In the case of pre-stretched materials, shown in Fig. 12 for the same material, the progression of the two curves is much more similar. The pre-stretching previous to the cyclic loading of the strain controlled tests has taken up some of the materials hardening ability, the material is already stronger due to pre-stretching than in its' state of delivery. Consequently the ability for further strengthening due to work hardening in the strain controlled tests is reduced. In fact the strength of the specimen subjected to the varying loads of an Incremental Step test is lower than the specimen subjected to single load step testing.

\section{Prediction of stress-strain curve dependant of degree of forming}

The large changes of the cyclic stress-strain curves resulting from the forming influences previously described make exact knowledge of the actual stress-strain curve for the current state of forming necessary, if accurate fatigue life estimates are to be achieved. Even small variations of the equivalent state of forming influence the cyclic curves strongly, as already shown in Fig. 6. Should these curves be used for a finite element based fatigue life calculation, the results will be accurate for the range of forming experimentally verified. This experimental method of determining stressstrain curves, though, is impractical due to the infinite amount of different states of forming in a typical deep drawn structure. The cost, time and effort of the experimental approach are prohibitive.

Therefore a method must be devised to easily mathematically describe the influence of forming for the given material using as basis a single stress-strain curve derived experimentally or from literature. Making use of existing material laws to estimate the progression of the stress-strain and strain-life curves for any state of forming will not lead to success with the austenitic steels at hand here, as the models are based on conventional deep drawing quality ferritic steels which show a strongly different hardening behaviour due to forming, their work hardening behaviour during cyclic loading also differs strongly. 
During the analyses of the numerous cyclic tests undertaken with the material 1.4301 it was found that the progression of the cyclic yield strength $R_{p 0,2}^{\prime}$ and the cyclic hardening coefficient $K^{\text {' }}$ show an almost linear dependency from the equivalent state of forming $\varphi_{\mathrm{v}}$. This progression of the coefficients is plotted over the state of forming in Fig. 13.

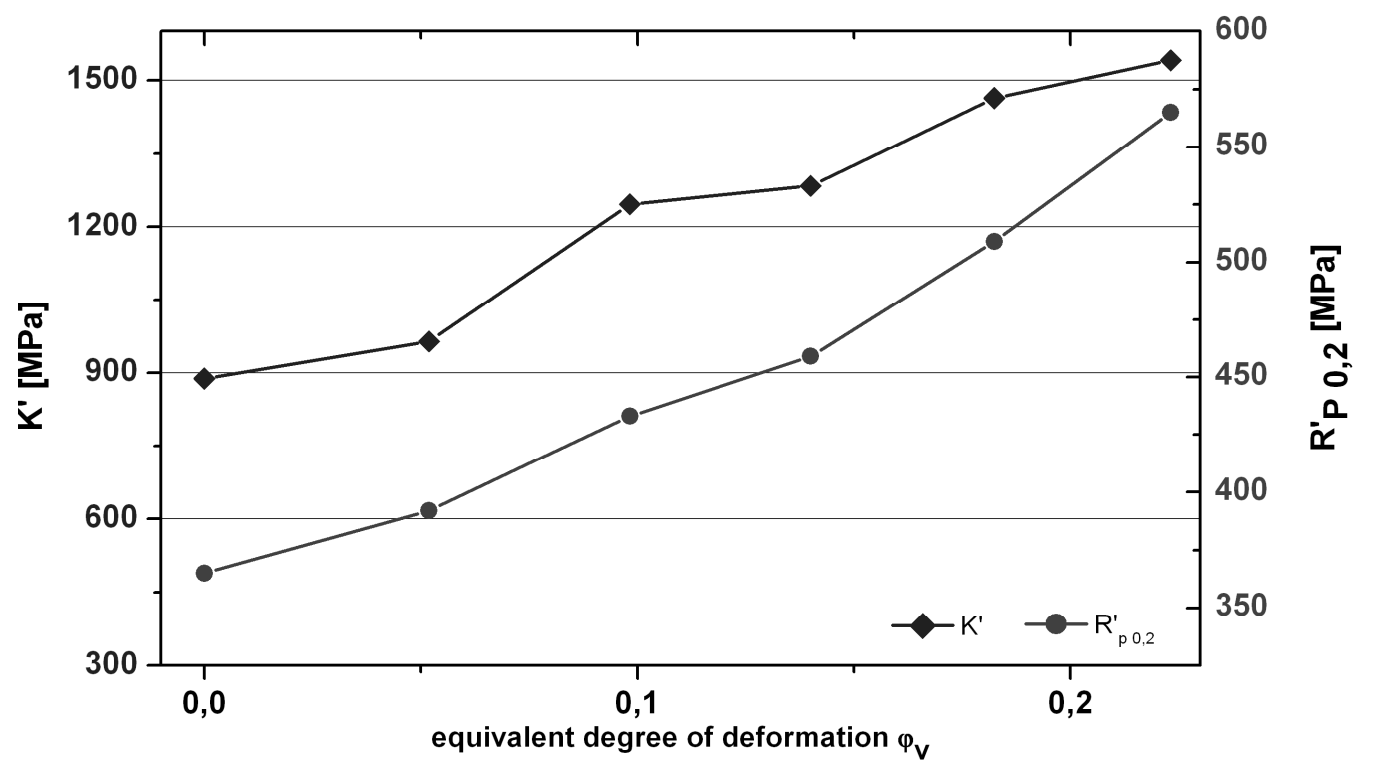

Fig. 13: cyclic coefficient of hardening and cyclic yield strength over equivalent state of forming

The cyclic stress-strain curve is described with Eq. 7 according to Manson-Coffin [2],[3] . Four variables are used to calculate the elastic and plastic strain respectively, one being Young's Modulus $E$ which is assumed to be constant for metals, the second the stress amplitude $\sigma_{\mathrm{a}}$, the remaining two are the cyclic parameters, the hardening coefficient $K^{\prime}$ and the hardening exponent $n$ '.

$$
\varepsilon_{\mathrm{a}, \mathrm{t}}=\varepsilon_{\mathrm{a}, \mathrm{e}}+\varepsilon_{\mathrm{a}, \mathrm{p}}=\frac{\sigma_{\mathrm{a}}}{\mathrm{E}}+\left(\frac{\sigma_{\mathrm{a}}}{\mathrm{K}^{\prime}}\right)^{\frac{1}{\mathrm{n}^{\prime}}}
$$

The progression of the cyclic hardening exponent $n$ ' does not follow a linear manner, making the fitting of a suitable function more complex, also the influence of small errors in the approximation of $n$ ' result in large errors in the stress strain curve due to the power of $n$ ' being the exponent. A more robust way of defining the position of the cyclic stress-strain curve is to use another supporting point for the curve, rather than the two cyclic parameters shown in Fig. 14.

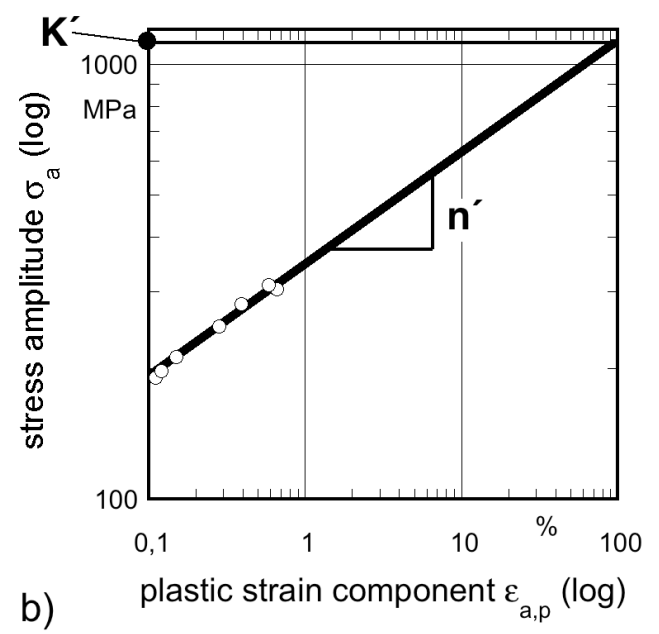

Fig. 14: illustration of cyclic parameters used to describe the cyclic stress-strain curve 
As shown by Fig. 13 the cyclic hardening coefficient can be approximated using a linear function, in the case of the material 1.4301 this linear function is shown in Eq. 8.

$$
K^{\prime}=888+2926 * \varphi_{v}
$$

The same holds true for the cyclic yield strength, in this case the linear fit is described by Eq. 9 .

$$
R_{p 0,2}^{\prime}=353+875^{*} \varphi_{v}
$$

These two parameters are sufficient to describe the progression of the cyclic stress-strain curve if the Manson Coffin equation is transposed to form Eq. 10.

$$
n^{\prime}=\frac{\log \left(\frac{R_{p 0,2}^{\prime}}{K^{\prime}}\right)}{\log (0,2)}
$$

Using this simple equation, the missing cyclic parameter for the Manson-Coffin equation can be determined. The parameters of the cyclic stress-strain curve are then fully described using the assumption that the cyclic yield strength $\mathrm{R}_{\mathrm{p} 0,2}$ and the cyclic hardening coefficient follow a linear progression over the magnitude of equivalent deformation. This certainly holds true for the levels of equivalent deformation experimentally verified here. An example of a predicted stress-strain curve

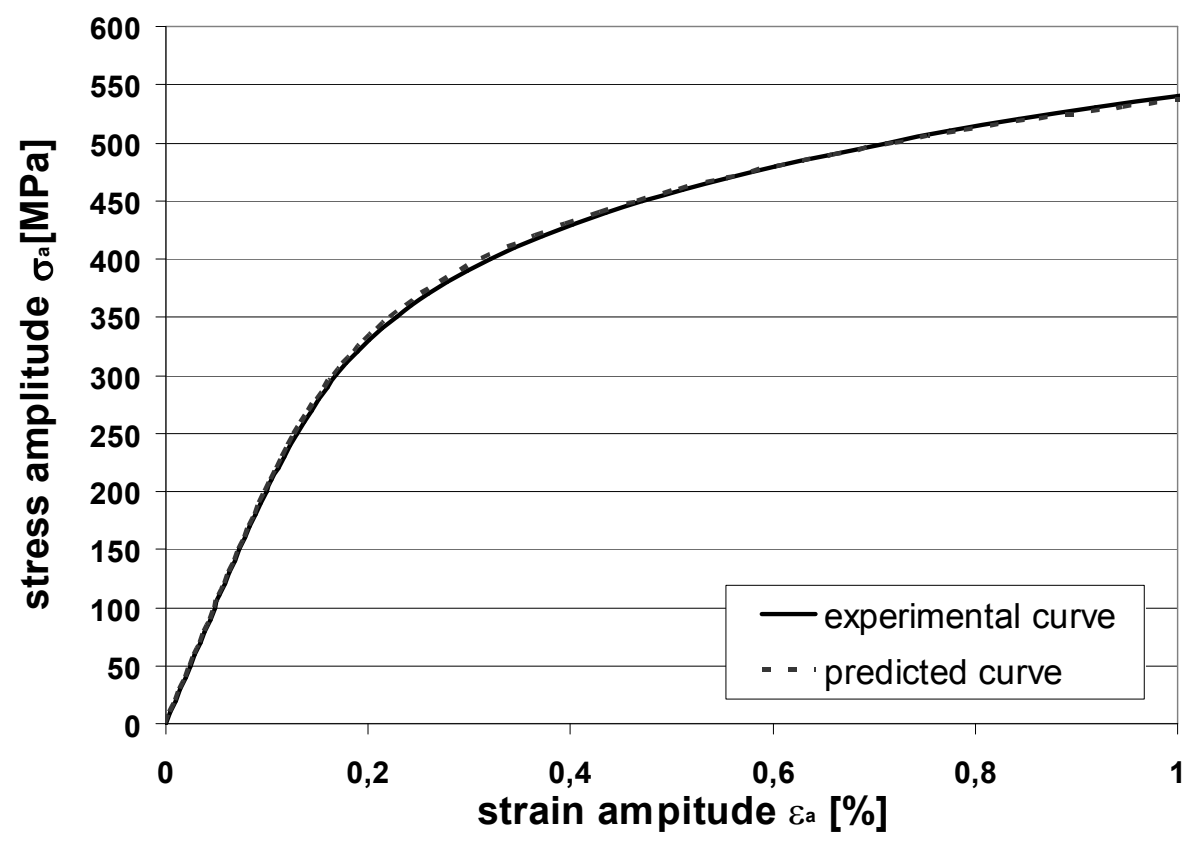

Fig. 15: Comparison of predicted stress-strain curve and experimentally determined curve for 1.4301, for $\varphi_{\mathrm{v}}=0,1$

compared to an experimentally determined curve is shown in Fig. 15 . The very small deviation of the predicted curve to the actually measured curve is negligible, making this simple method of determining the progression of the equivalent forming dependant stress-strain curve very suitable for the direct inclusion in finite element calculation models. This would enable a stress strain curve to be calculated for each element of a simulation model, enabling the exact calculation of stresses and strains resulting from outer loads. This would enable the fatigue life prediction to be more accurate than possible without the inclusion of such information. 


\section{Transient behaviour of austenitic steels, 1.4301}

The strong influence of forming on the cyclic stress-strain and strain-life curves was shown in the previous chapters of this paper. It was also shown that the potential for work hardening during the fatigue lifetime of an austenitic steel depends strongly on two factors. The first, and most influential is the strain amplitude the material is subjected to. As the different progressions of cyclic stressstrain curves derived from single load step tests compared to Incremental Step Tests (Fig. 11) show, the repetition of large strain amplitudes during Incremental Step Tests leads to cyclic work hardening, the stress strain curve is lifted above the single load step test curve, effectively resulting in a stronger material at half of its fatigue life. The second factor which influences the progression of stress-strain curves is the amount of preforming the material is subjected to prior the cyclic loading. Here, large amounts of deformation reduce the materials' capability for further work hardening as a result of cyclic loading. As a consequence the cyclic stress-strain curves of single load step tests and Incremental Step Tests are similar (Fig. 12). This behaviour strongly influencing the cyclic stress-strain curves is specific to austenitic steels, as these offer a large potential for work hardening not normally found in ferritic or martensitic steels, which have a neutral cyclic behaviour, meaning they show no dominant cyclic hardening or softening at large strain amplitudes.

To visualise the work hardening behaviour the recorded test data of numerous Incremental Step Tests was analysed to specifically describe the progression of the stress amplitudes over the specimens fatigue life. Normally only one block of increasing strain steps is analysed to calculate the specimens stress-strain curve from the complete test. This block is always the block at half the specimens fatigue life. The drawback of this approach is the fact that the material constantly changes its' cyclic behaviour during the test, meaning the calculated stress-strain curve is at best a representation of an average stress-strain curve, but does not accurately represent the cyclic behaviour at the beginning or the end of the specimens' fatigue life.

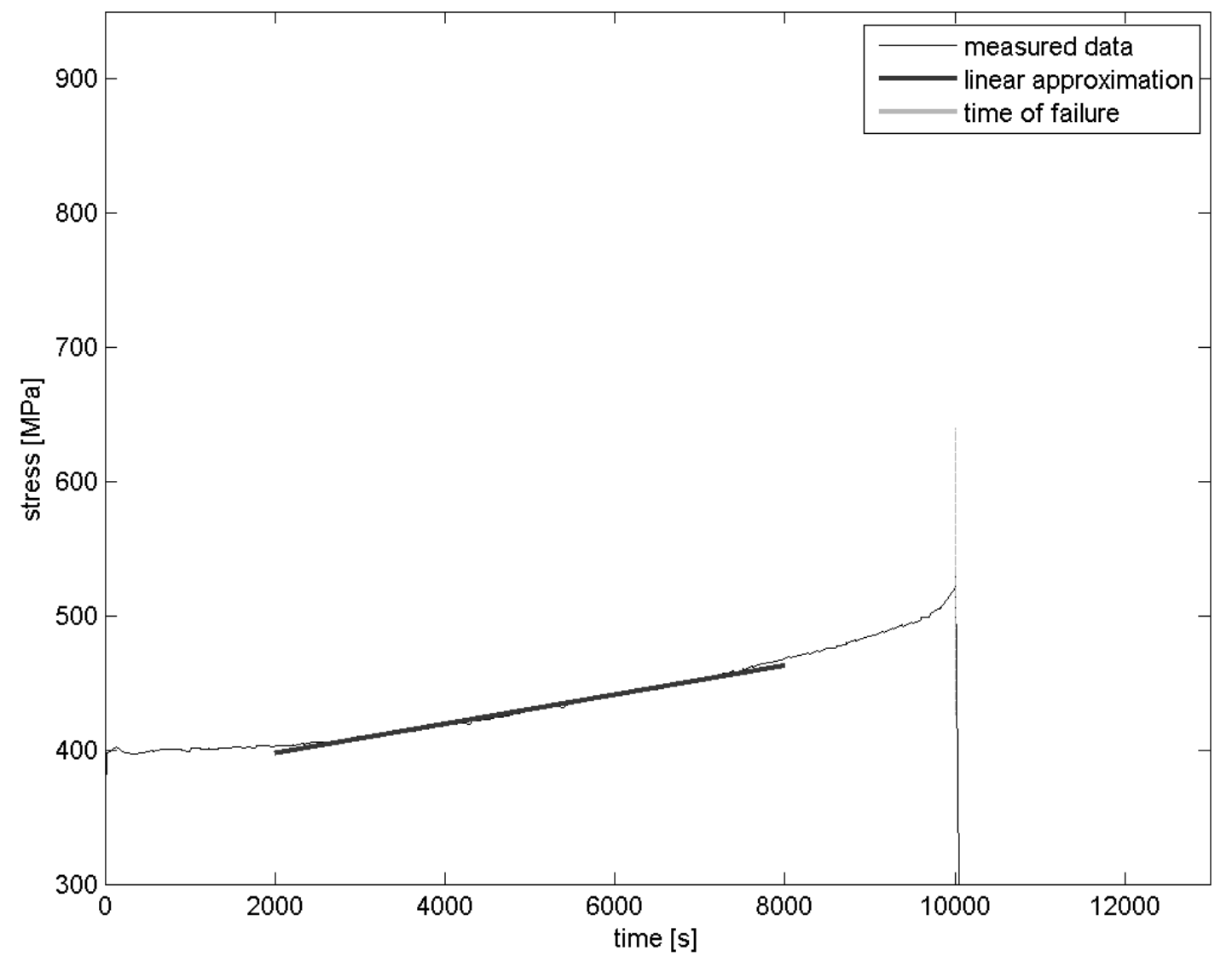

Fig. 16: progression of maximum stress amplitudes during IST, 1.4301 in state of delivery 
The progression of the maximum stresses over time is shown in Fig. 16. The recorded test data is filtered to only show the stresses resulting from $8 \%$ strain amplitudes in this plot. The material is 1.4031 in the state as delivered, the strain amplitude are constant throughout the test. The abscissa shows the test time, one block of an IST takes 110 seconds as a guide to the number of blocks the material has been subjected to.

It is clearly evident that are large amount of work hardening takes place in this material as a result of the strain controlled high amplitude loading. There is no apparent softening at the beginning of the test. The maximum stresses rise from around $400 \mathrm{MPa}$ at the beginning of the test to around $530 \mathrm{MPa}$ just before failure of the specimen. This is equivalent to a $30 \%$ increase in the cyclic strength between the state of delivery without cyclic loading and the state of high fatigue after cyclic loading. Consequently, the cyclic parameters describing the stress-strain curve would vary largely depending on the current state of fatigue, with obvious negative effects on the accuracy of a numerical fatigue life calculation.

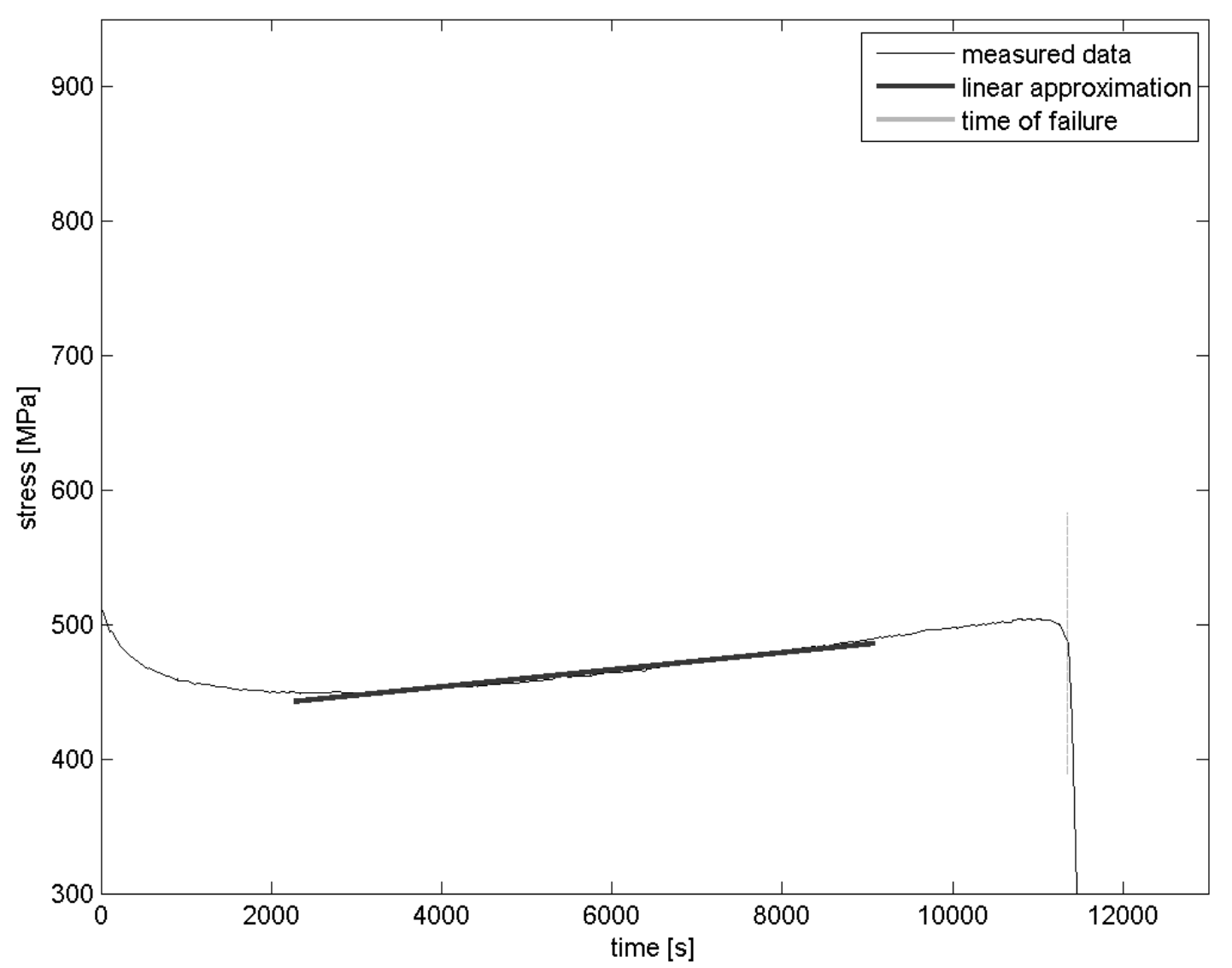

Fig. 17: progression of maximum stress amplitudes during IST, 1.4301 with 5\% pre-stretch

For $5 \%$ of pre-stretch the progression of the maximum stresses is slightly different compared to the state of delivery. At the beginning of the test there is a small amount of cyclic softening, the initial stress of around $520 \mathrm{MPa}$ fall to around $460 \mathrm{MPa}$ before cyclic hardening set in for the rest of the specimens fatigue life. Just before failure, the maximum stress amplitude of $510 \mathrm{MPa}$ is reached. The progression of the curve is almost linear over most of its length, the cyclic hardening can be described as linear to the number of strain cycles. 


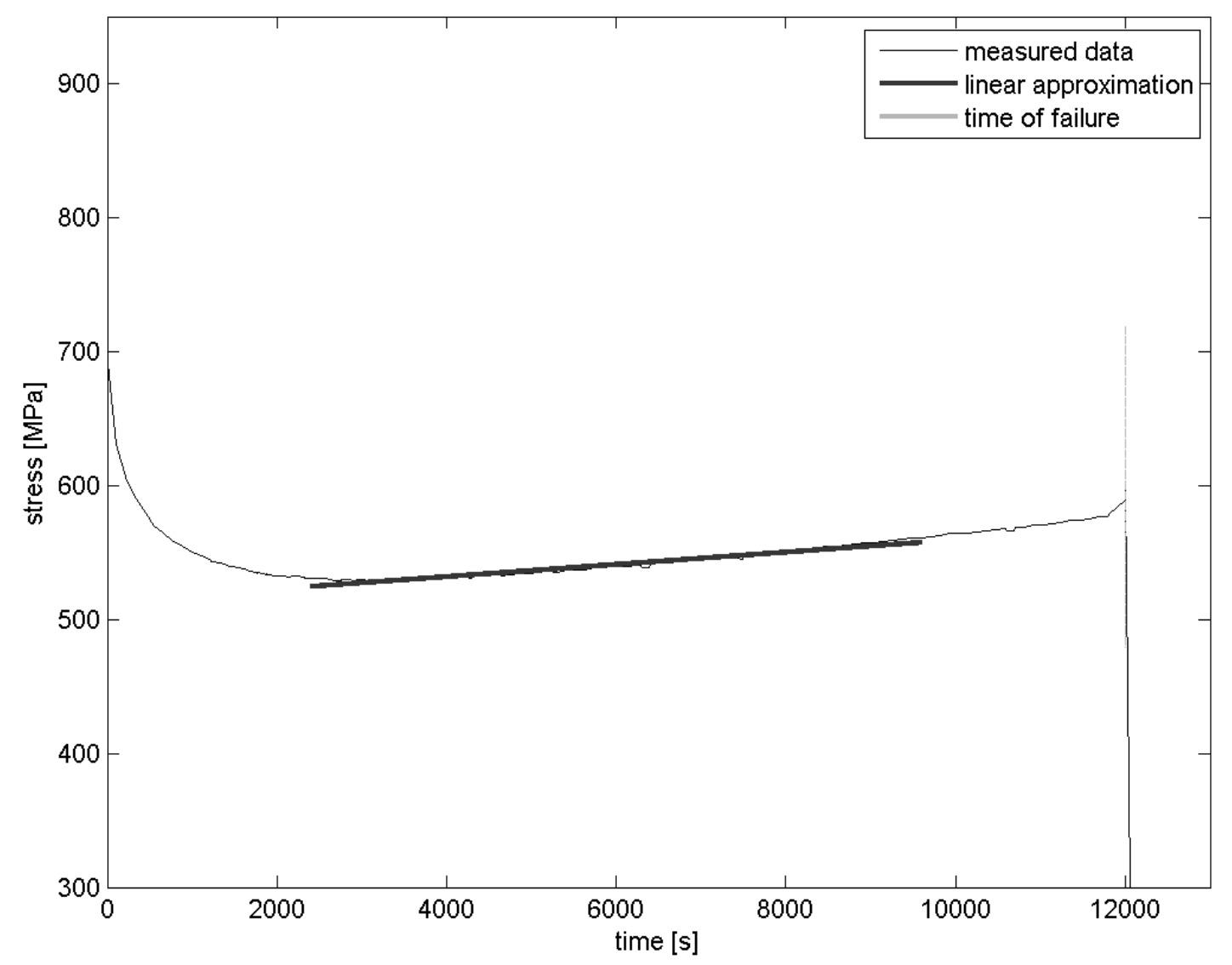

Fig. 18: progression of maximum stress amplitudes during IST, 1.4301 with $15 \%$ pre-stretch

The positive effects of pre-stretching on the static tensile strength are clearly visible in Fig. 18. During the first few cycles of the IST, the maximum stress amplitudes fall sharply from $680 \mathrm{MPa}$ to around $550 \mathrm{MPa}$, before the effects of work hardening lead to a slow increase of cyclic strength for the rest of the test. At the very end of this specimens fatigue life a maximum stress amplitude of around $590 \mathrm{MPa}$ is reached, less than at the beginning of the test, but still higher than the specimen with only $5 \%$ of pre-stretch. After the initial softening of the material at the beginning of testing, the work hardening is linear until failure of the specimen, meaning that not all the martensitic evolution has been used during pre-stretching. 


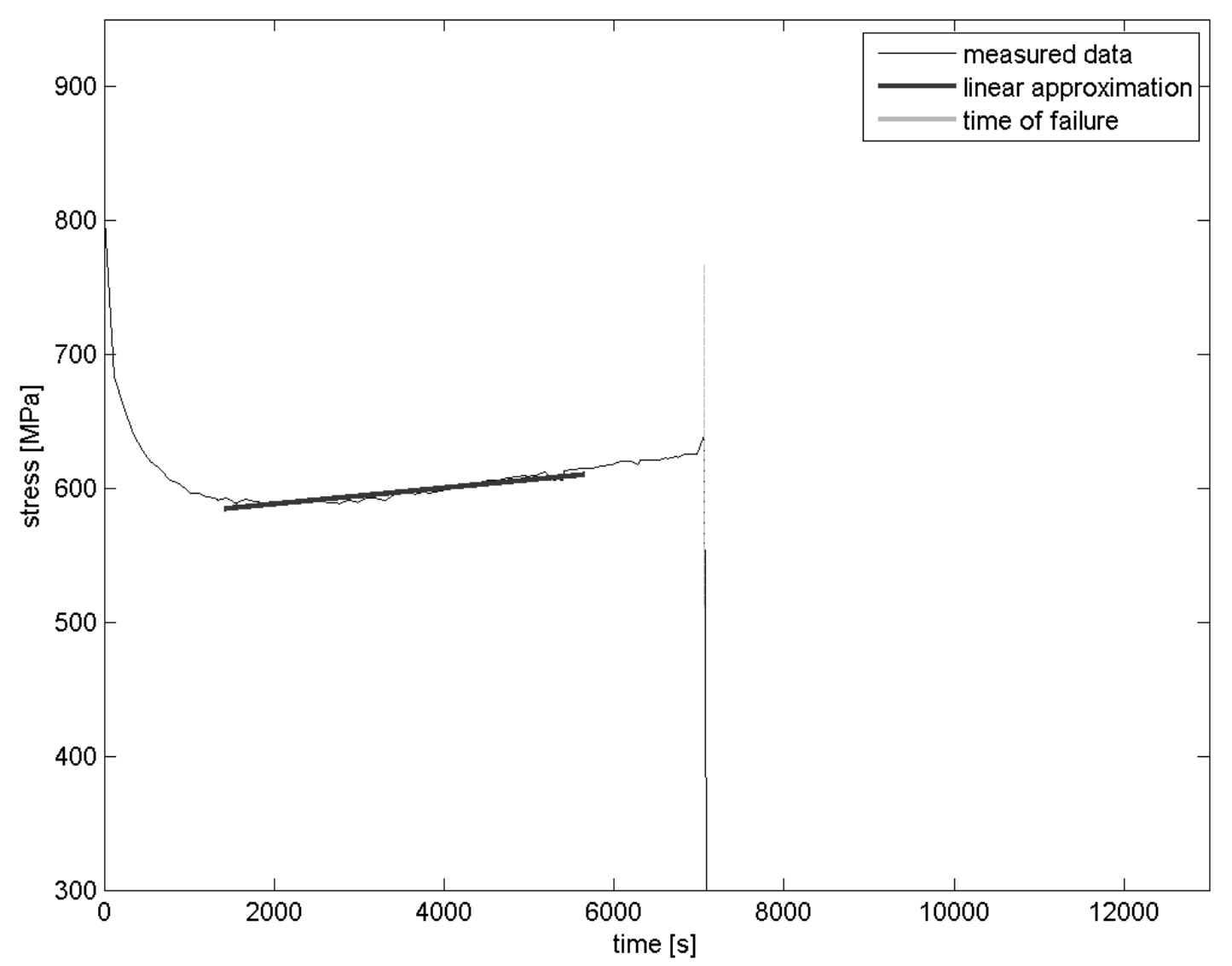

Fig. 19: progression of maximum stress amplitudes during IST, 1.4301 with $20 \%$ pre-stretch

The plot of a specimen with $20 \%$ of pre-stretch is shown in Fig. 19. The quasi static stress during the first cycle of testing reaches almost $800 \mathrm{MPa}$ in this case, before rapidly softening to stress levels of just under $600 \mathrm{MPa}$ after a few cycles of the IST. From this point on, linear work hardening sets in until failure of the specimen at a stress level of around $630 \mathrm{MPa}$. 


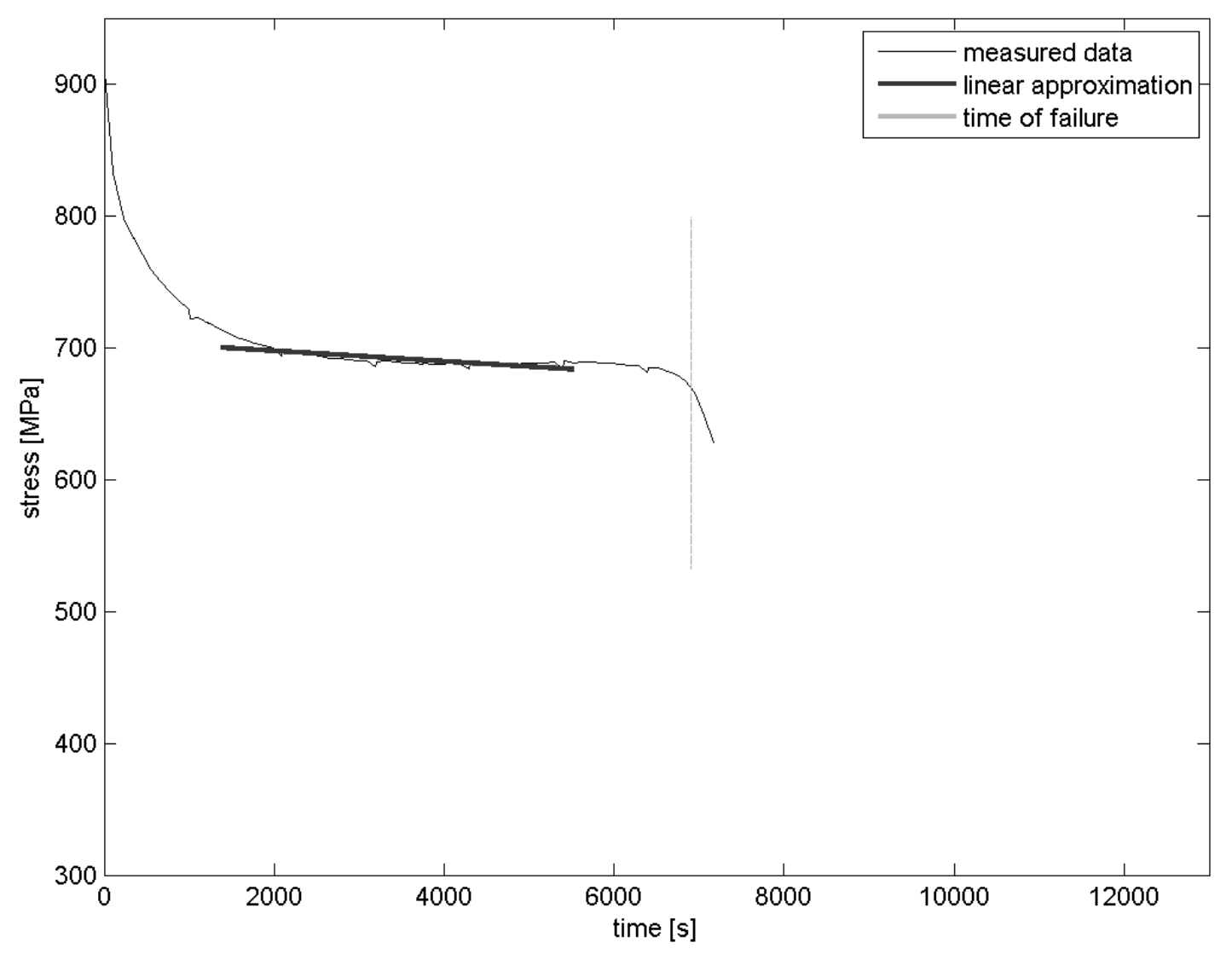

Fig. 20: progression of maximum stress amplitudes during IST, 1.4301 with $30 \%$ pre-stretch

The curve presented in Fig. 20 differs strongly form the previously shown trends of hardening behaviour. A very high initial stress of just over $900 \mathrm{MPa}$ drops sharply during the first load cycles to around $700 \mathrm{MPa}$. From here on the curve stabilises and shows a regular progression until failure. The significant difference to the previous plots is that no further work hardening takes place during cyclic loading. In fact there is a small constant amount of cyclic softening over the fatigue life. Nonetheless, the overall stress level is significantly higher than for the other states of pre-stretching, making the process of pre-stretching very worthwhile for this material. The absence of further cyclic hardening in this state of pre-stretching indicated that full martensitic evolution has taken place previous to the cyclic testing, leaving no further strengthening potential during due to cyclic hardening.

To sum up the influence of forming on the progression of cyclic stresses, it is evdient from the plotted figures that the effects of work hardening are strongly dependant on the straining of the material during cyclic testing. Generally speaking, cyclic loading causes two opposing effects in the material if pre-stretched before testing. The first is a softening during the first $10-20 \%$ of the specimens fatigue life, resulting in a noticeable reduction of stress amplitudes. The strengthening caused by pre-stretching is reduced by up to $25 \%$ during the first cycles of an Incremental Step Test. Proceding further, work hardening takes place after the first decline in stress amplitude, leading to an increase of stress amplitudes up to the point of fatigue induced failure. The increase of stress amplitude follows a linear progression in most cases, confirming the onset of work hardening. The initial reduction of stress may be caused by a reduction of hardening dislocation density, as a result of the large plastic strain amplitudes caused by cyclic testing. This effect is much stronger and of faster progression than the strain induced work hardening, which is also induced by plastic strain amplitudes, leading to a sharp fall of overall strength in the case of large degrees of preforming. Work hardening takes place from the very beginning of cyclic testing as shown for the case of Incremental Step Testing without pre-stretch, Fig. 16. This specimen shows no initial fall of cyclic stresses, work hardening effects can be seen from the very beginning of testing on. Although the initial softening seems fairly dramatic for high degrees of pre-stretching, the gains are 
nonetheless very substantial over the whole fatigue life. Whereas the material as delivered has a mean maximum stress amplitude of around $450 \mathrm{MPa}$, the $30 \%$ pre-stretched material has a mean stress amplitude of around $700 \mathrm{MPa}$, which equates to an increase of bearable stress of over $50 \%$ compared to a non pre-stretched specimen.

The effects of initial softening as a result of operating load induced strains and ensuing work hardening aren't yet taken into account in any material models or fatigue life calculations. The development of a model to account for these effects should therefore by subject of future work in this area.

\section{Influence of forming temperature of simple additional stiffening geometries}

Making practical use of the great potential of strengthening austenitic and residual austenite steels by deformation induced hardening is off course also of great interest to industry. A common problem of large thin sheet metal structures is a lack of stiffness in large, flat areas without additional stiffening elements such as supporting sections or stiffening frames. These secondary structures to support large thin sheets add to the cost, complexity and weight of such parts. A method of stiffening these sheets without the need for additional materials and manufacturing steps is to form additional stiffening geometries into the thin sheet plates. These additional stiffening geometries may be small round dimples, such as used here, or other geometrical shapes such as lozenges, squares or line shaped elements. Currently research is still taking place on the ideal shape and placement as well as denseness of these additional geometries.

Practical experiments were undertaken in cooperation with the part project A1 (IFUM) to asses the fatigue life and temperature influence on forming of these additional stiffening elements. The IFUM undertook numerical simulations of the forming process, resulting in a detailed model of the formed parts, their residual stresses, the equivalent deformation and exact geometry. Additionally, prototype parts were deep drawn from two materials on the IFUM press, so that fatigue life experiments could be undertaken on parts drawn form TRIP700 and 1.4301. These hat profiles shown in Fig. 21 were manufactured at three different temperatures using a temperature controlled die, making it possible to set the forming temperatures to $-20{ }^{\circ} \mathrm{C}, 20{ }^{\circ} \mathrm{C}$ and $100{ }^{\circ} \mathrm{C}$. As previously mentioned, the evolution of deformation based martensite in an austenitic steel is strongly dependant on the temperature at which the straining occurs. Lower than room temperatures typically favour the martensitic evolution, temperatures above $60{ }^{\circ} \mathrm{C}$ inhibit any forming of martensite. 
max. principal stress [MPa]
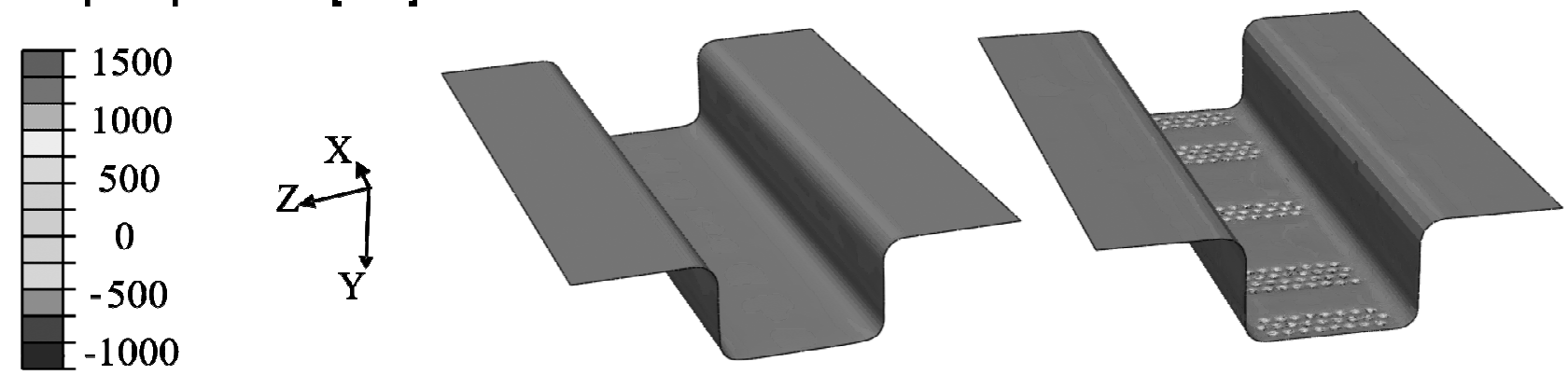

\section{degree of forming [-]}
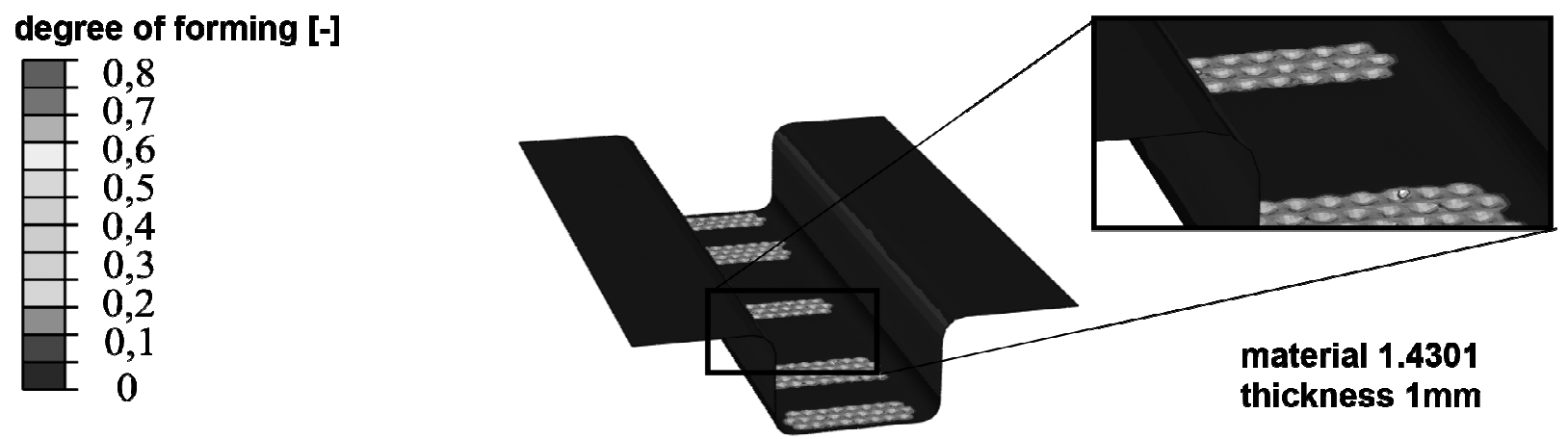

Fig. 21: Forming simulation of hat profile with additional forming elements (courtesy of IFUM Hannover)

Specimens were machined from the basic hat profile according to Fig. 22 , the additional forming elements were always placed in the centre of the specimen in the parallel area, a close up of the round elements used in this experiment are shown in Fig. 23.

The specimens were cyclically loaded with a single load step on an hydraulic test stand under a stress ratio of $\mathrm{R}=0.1$. For the 1.4031 material a stress amplitude of $140 \mathrm{MPa}$ was chosen for the tests, the TRIP700 material was tested at $20^{\circ} \mathrm{C}$ and later a S-N curve was generated with stress amplitudes between $200 \mathrm{MPa}$ and $240 \mathrm{MPa}$. The aim was to get comparative fatigue life figures in dependency of the forming temperature, and therefore allow conclusions to be drawn from the fatigue life behaviour on the martensitic evolution during temperature controlled forming.

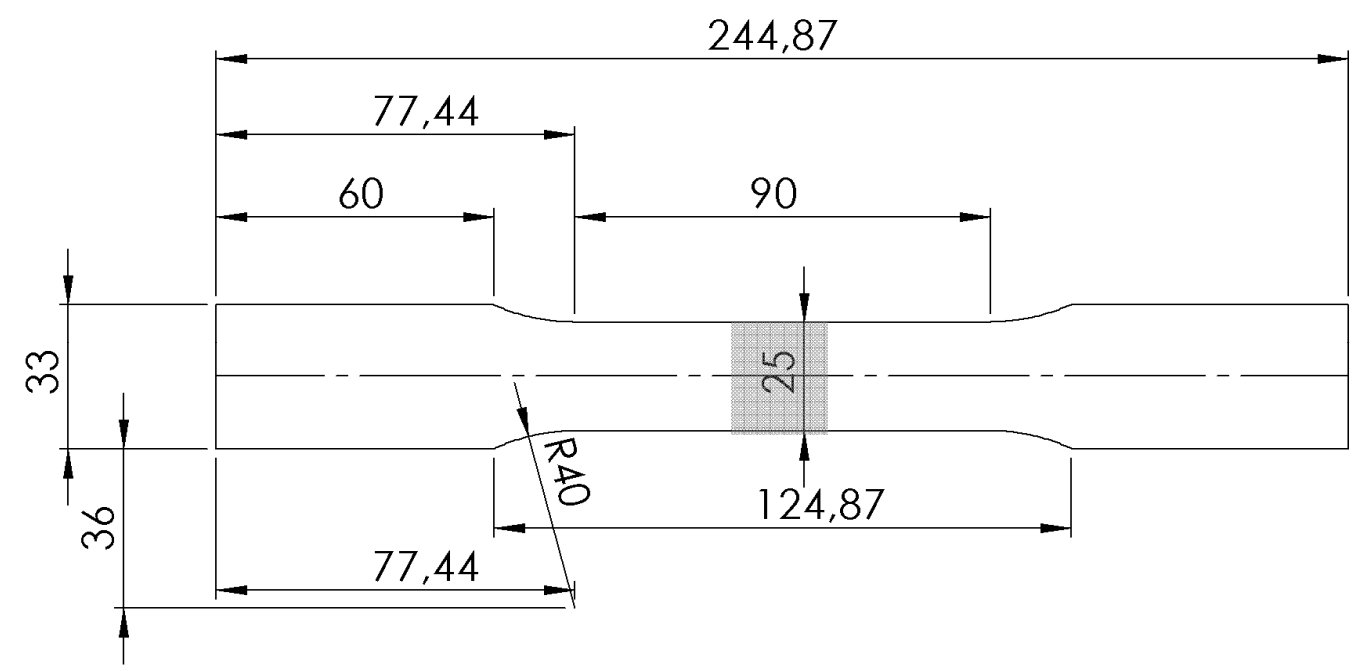

Fig. 22: geometry of test specimen for testing of additional forming elements, forming area hatched 


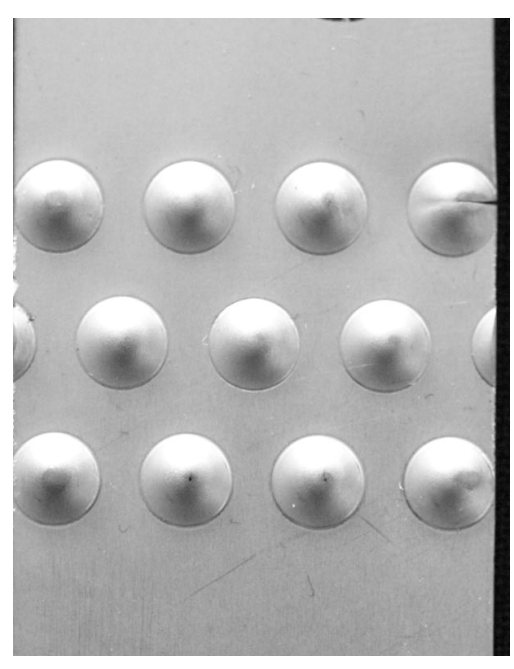

Fig. 23: close up of specimen with additional forming elements

The test results for the TRIP700 material are shown in Fig. 24 for the single stress amplitude comparative tests. A noticeable influence of the forming temperature on the fatigue life performance of this material is evident. Under identical test conditions the specimens with the additional forming elements produced at $100^{\circ} \mathrm{C}$ showed the best fatigue performance, the specimens formed at $-20^{\circ} \mathrm{C}$ showed less fatigue life than the specimens formed a room temperature.

A S-N curve was also experimentally determined for this material, Fig. 25. This curve shows the same effects as the single tests undertaken previously. A marked influence of the forming temperature on the fatigue life is evident. Here, again, higher forming temperatures result in an increased fatigue life performance compared to room temperature forming. Forming at $-20{ }^{\circ} \mathrm{C}$ reduces the fatigue life. A larger span of stress amplitudes could not reliably be tested due to cyclic creeping taking place at higher stress levels. Fatigue endurance limit tests to determine the exact endurance limit were not undertaken.

These results are unusual in as far as the forming of hard martensite from the residual austenite phase in the TRIP material is probably not responsible for the increased fatigue life. It is expected that martensitic evolution is inhibited at temperatures of $100{ }^{\circ} \mathrm{C}$. Nonetheless, some strengthening has taken place compared to room temperature forming. Other material properties must be the cause of this behaviour, which has still be analysed further. 


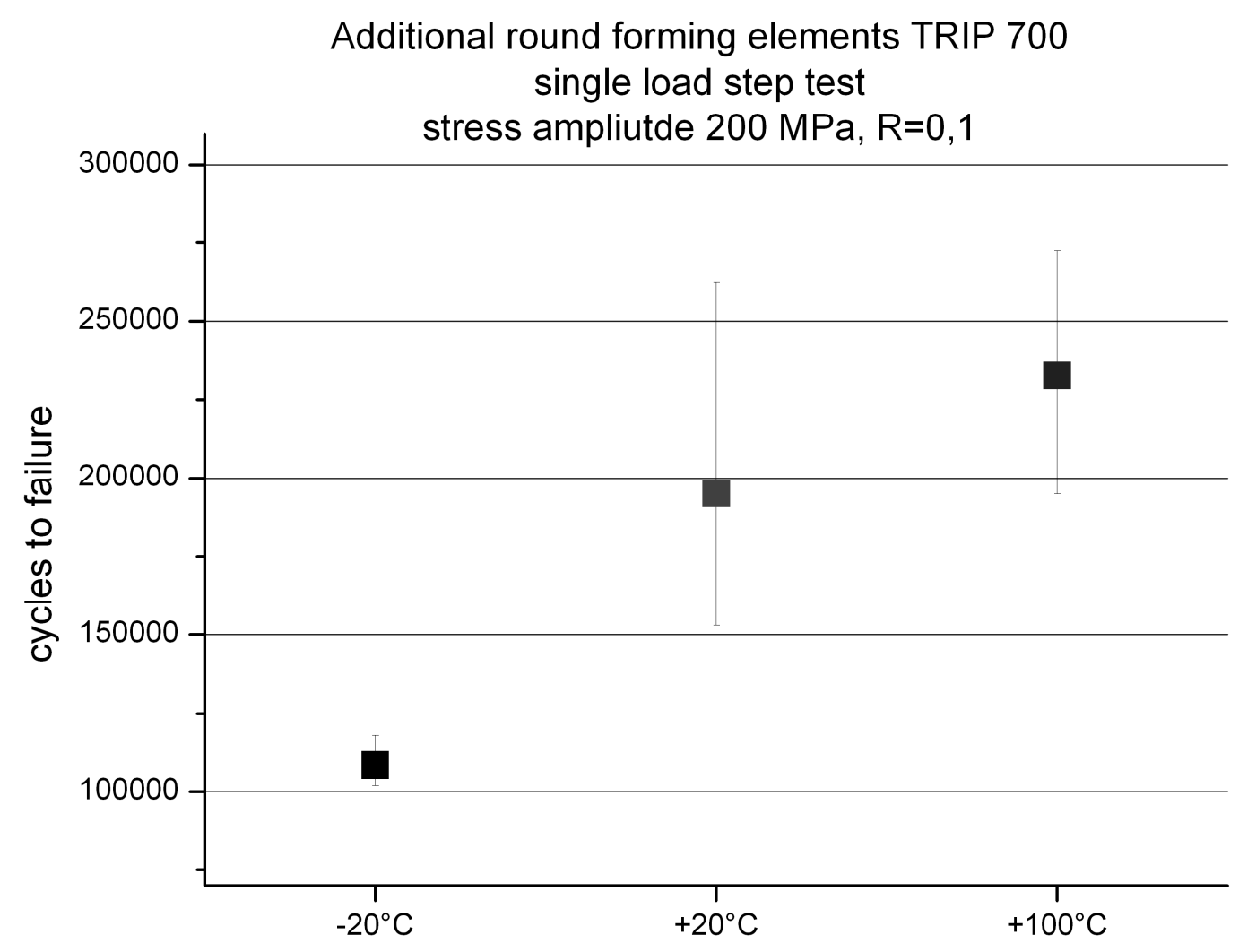

Fig. 24: Influence of forming temperature on fatigue life of TRIP 700 for constant stress amplitude loads

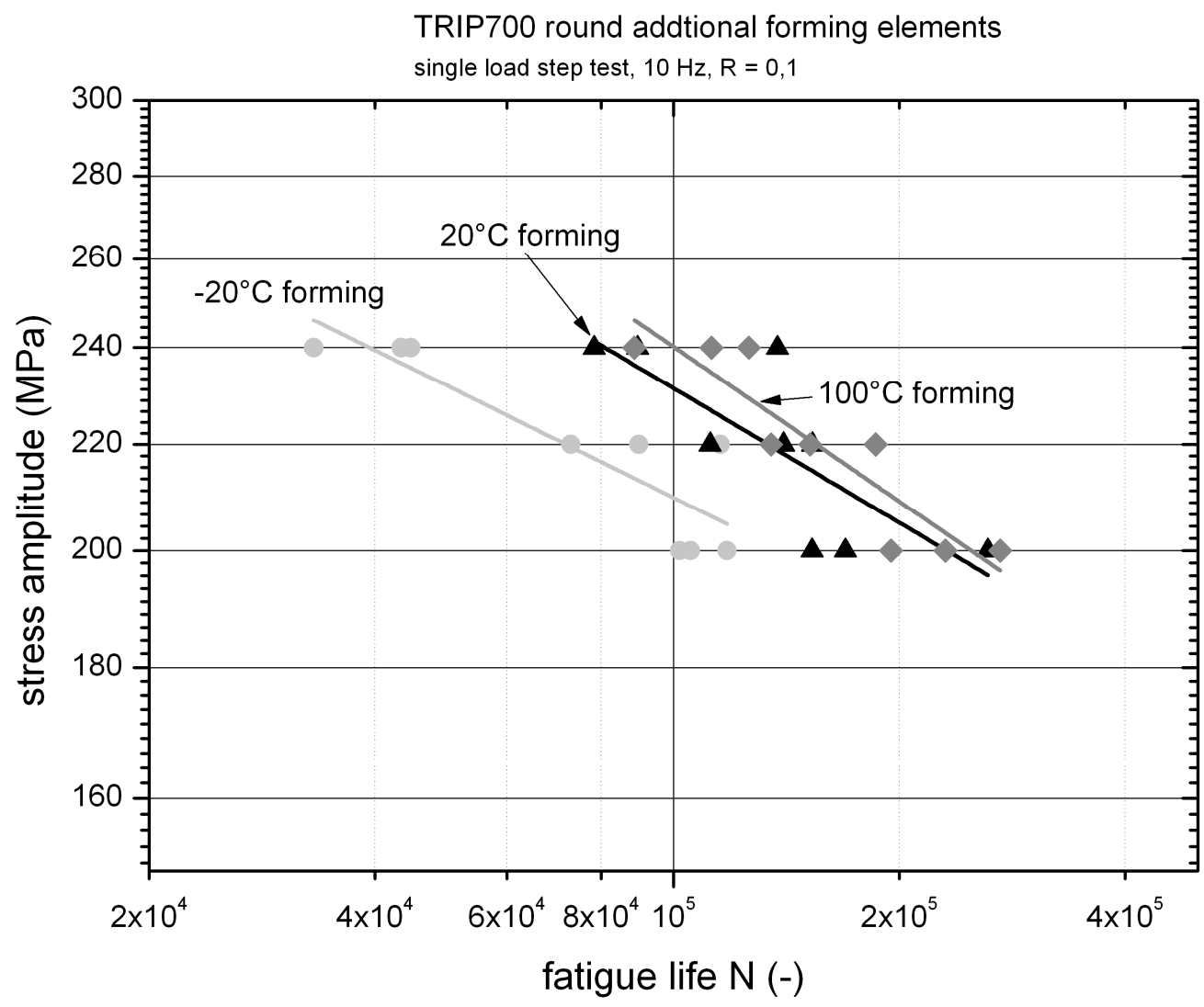

Fig. 25: SN-curve showing influence of forming temperature on fatigue life of TRIP700 under constant amplitude loading 
The austenitic steel 1.4301 was also tested under identical conditions as the TRIP material. Specimens were formed at $-20^{\circ} \mathrm{C}, 20^{\circ} \mathrm{C}$ and $100^{\circ} \mathrm{C}$, followed by machining identical specimens to those previously described. The stress amplitude for the fatigue tests was adjusted to this materials' lower strength, so that the stress amplitude for the single load step tests was set to $140 \mathrm{MPa}$. The results of these tests are shown in Fig. 26. This austenitic material shows a clear influence of the forming temperature on the fatigue life of the tested specimens. Cooled forming at $-20{ }^{\circ} \mathrm{C}$ leads to an increase of fatigue life, whereas hot forming at $100^{\circ} \mathrm{C}$ leads to a reduction of the fatigue life. Although the differences in the fatigue life of the $20^{\circ} \mathrm{C}$ and $100{ }^{\circ} \mathrm{C}$ specimens is only small, the increased life of the cold formed specimens is noticeable.

These results confirm the positive effects of martensitic hardening induced by straining the material above its elastic limit for the fatigue life performance. A greater amount of austenite is transformed when cooled forming is undertaken compared to room temperature forming, resulting in an improved fatigue performance. The least fatigue resistance is shown for the $100{ }^{\circ} \mathrm{C}$ specimens, confirming the assumption that martensite formation is inhibited by hot forming in this material.

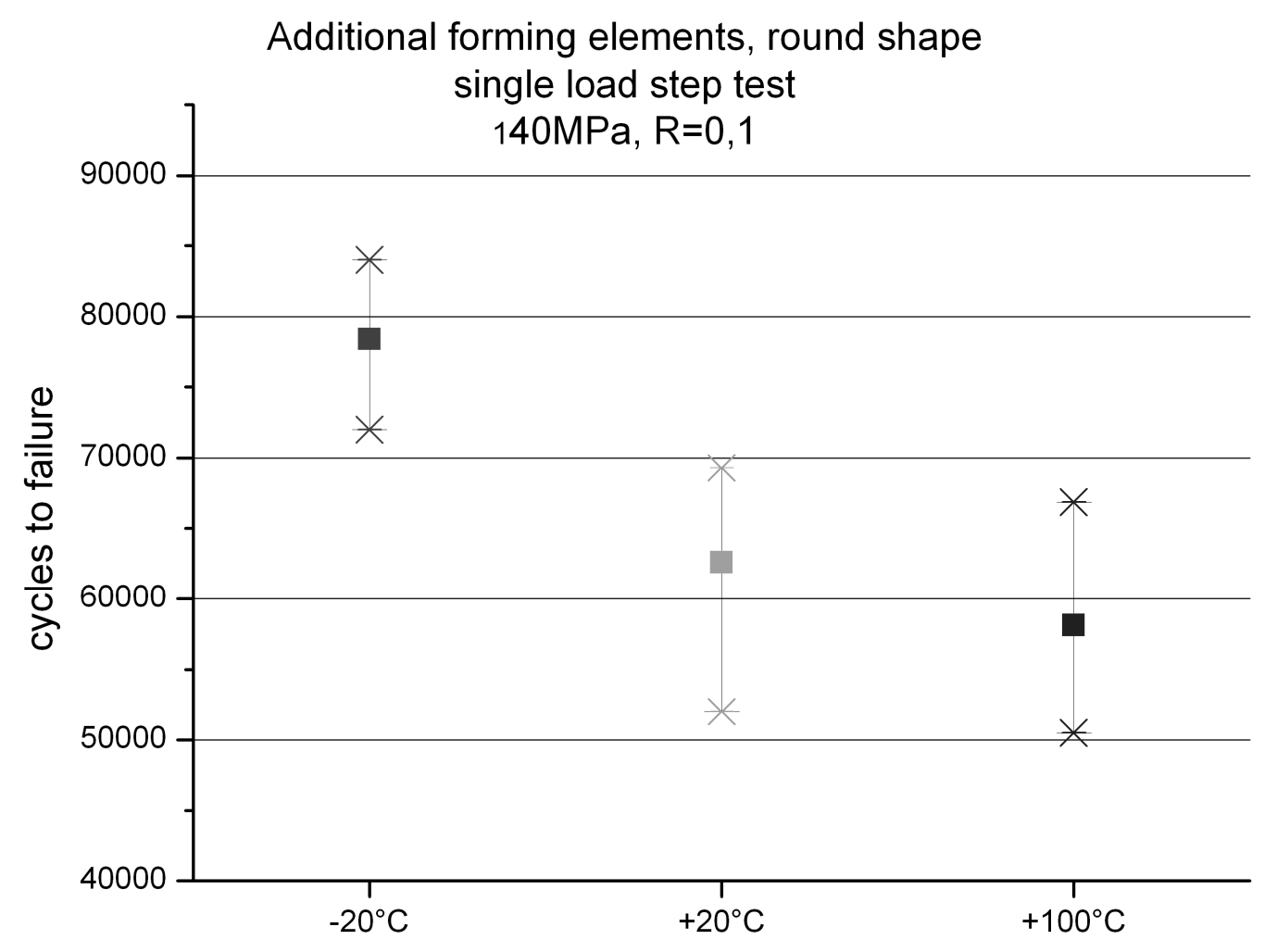

Fig. 26: Influence of forming temperature on fatigue life of 1.4301 for constant stress amplitude load

\section{Summary}

Various forming and manufacturing influences were investigated in described experimental proceedings, all of them aiming at a more accurate description of the cyclic behaviour of thin metal sheets during cyclic loading. The materials tested were TRIP700/780, a material with an residual austenitic phase, as well as fully austenitic steels. It was shown that forming has a large influence on the progression of cyclic stress-strain curves, the positive effect of various degrees of forming are particularly obvious when austeintic stainless steels are cyclicly loaded. Great increases in stress amplitudes for given strain amplitudes were achieved as a result of pre-stretching, resulting directly in improved fatigue life for given loads. A model to describe the influence of forming for the material 1.4301 was developed, allowing the prediction of cyclic stress-strain curves for arbitrary degrees of forming. Furthermore, the progression of cyclic softening as a result of plastic straining 
and work hardening as a result of further operating-like loading was described in connection with pre-forming the material. The resulting discontinuous progression of stress levels during Incremental Step Tests indicate the need for further work to take into account the contrary effects of softening due to reduced dislocation density and work hardening resulting from operational straining.

Other influences on the fatigue life of simple part-like geometries were investigated in cooperation with project A1, where additional forming elements were impressed into thin steel sheets to primarily improve the sheets stiffness. It was shown that the fatigue performance of such geometrical stiffening elements can be improved by temperature controlled forming. Changing the forming temperature of a die to suitable values for the material being formed can lead to an increase of fatigue life compared to forming at room temperature. A temperature reduction can, for example, favour the evolution of martensite in the material during forming, enhancing its mechanical and cyclic properties.

\section{References}

[1] SEP 1240: Testing and Documentation Guideline for the Experimental Determination of Mechanical Properties of Steel Sheets for CAE-Calculations, Stahlinstitut VDEh 1st Edition, (2006)

[2] L.F. Coffin: A study of the effects of cyclic thermal stresses on a ductile metal, Trans. ASME, Nr. 76, pp. 931-950, (1954)

[3] S.S. Manson: Fatigue: A complex subject - some simple approximations, Experimental Mechanics 5, Nr. 7, pp. 45-87, (1965)

[4] W. Ramberg, W.R. Osgood: Description of stress-strain curves by three parameters, Technical Report Technical Note No. 902, NACA (1943)

[5] R. Wagener, M. Schatz: Leichtbau mit Hilfe von zyklischen Werkstoffkennwerten für Strukturen aus umgeformten Feinblech, Bericht Nr. 191, Forschungsvereinigung Automobiltechnik, (2005)

[6] G. Steinbeck, W. Bleck, B. Engl, A. Frehn, D. Nicklas, H.-M. Sonne, C.M. Sonsino, H. Kaufmann, R. Masendorf, A. Hatscher, H. Zenner, C.-P. Bork, J. Hinterdorfer: Ermittlung von Berechnungskennwerten für Karosseriestähle - Ein Gemeinschaftsprojekt der Stahl- und Automobilindustrie, Materialwissenschaften und Werkstofftechnik 35 (2004) Nr. 8

[7] R.W. Landgraf, J. Morrow, T. Endo: Determination of the cyclic stress-strain curve. Journal of Materials 4 (1969) 1, pp. 176-188

[8] H.J. Bassler: Wechselverformungsverhalten und verformungsinduzierte Marteinsitbildung bei dem metastabilen austenitischen Stahl X6CrNiTi1810, Werkstoffkundliche Berichte, Band 6, Lehrstuhl für Werkstoffkunde der Universtität Kaiserslautern (1999) 